\title{
Proteomics analysis of bladder cancer invasion: Targeting EIF3D for therapeutic intervention
}

\author{
Agnieszka Latosinska ${ }^{1,2, *}$, Marika Mokou ${ }^{1,3, *}$, Manousos Makridakis ${ }^{1}$, William \\ Mullen ${ }^{4}$, Jerome Zoidakis ${ }^{1}$, Vasiliki Lygirou${ }^{1}$, Maria Frantzi ${ }^{2}$, Ioannis Katafigiotis ${ }^{5}$, \\ Konstantinos Stravodimos ${ }^{5}$, Marie C. Hupe ${ }^{6}$, Maciej Dobrzynski ${ }^{7}$, Walter Kolch77, \\ Axel S. Merseburger ${ }^{6}$, Harald Mischak ${ }^{2,4}$, Maria G. Roubelakis ${ }^{3,1}$ and Antonia Vlahou ${ }^{1}$ \\ ${ }^{1}$ Biotechnology Division, Biomedical Research Foundation, Academy of Athens, Athens, Greece \\ ${ }^{2}$ Mosaiques Diagnostics GmbH, Hannover, Germany \\ ${ }^{3}$ Laboratory of Biology, Department of Basic Medical Sciences, National and Kapodistrian University of Athens, School of \\ Medicine, Athens, Greece \\ ${ }^{4}$ BHF Glasgow Cardiovascular Research Centre, University of Glasgow, Glasgow, United Kingdom \\ ${ }^{5}$ Department of Urology, Medical School of Athens, Laikon Hospital, Athens, Greece \\ ${ }^{6}$ Department of Urology, Campus Lübeck, University Hospital Schleswig-Holstein, Lübeck, Germany \\ ${ }^{7}$ Systems Biology Ireland, Conway Institute, and School of Medicine, University College Dublin, Belfield, Dublin, Ireland \\ *These authors contributed equally to this work
}

Correspondence to: Antonia Vlahou, email: vlahoua@bioacademy.gr

Keywords: EIF3D, translation, bladder cancer, tissue proteomics, RHEB

Received: January 31, $2017 \quad$ Accepted: April 07, $2017 \quad$ Published: April 20, 2017

Copyright: Latosinska et al. This is an open-access article distributed under the terms of the Creative Commons Attribution License 3.0 (CC BY 3.0), which permits unrestricted use, distribution, and reproduction in any medium, provided the original author and source are credited.

\section{ABSTRACT}

Patients with advanced bladder cancer have poor outcomes, indicating a need for more efficient therapeutic approaches. This study characterizes proteomic changes underlying bladder cancer invasion aiming for the better understanding of disease pathophysiology and identification of drug targets. High resolution liquid chromatography coupled to tandem mass spectrometry analysis of tissue specimens from patients with non-muscle invasive (NMIBC, stage pTa) and muscle invasive bladder cancer (MIBC, stages pT2+) was conducted. Comparative analysis identified 144 differentially expressed proteins between analyzed groups. These included proteins previously associated with bladder cancer and also additional novel such as PGRMC1, FUCA1, BROX and PSMD12, which were further confirmed by immunohistochemistry. Pathway and interactome analysis predicted strong activation in muscle invasive bladder cancer of pathways associated with protein synthesis e.g. eIF2 and mTOR signaling. Knock-down of eukaryotic translation initiation factor 3 subunit D (EIF3D) (overexpressed in muscle invasive disease) in metastatic T24M bladder cancer cells inhibited cell proliferation, migration, and colony formation in vitro and decreased tumor growth in xenograft models. By contrast, knocking down GTP-binding protein Rheb (which is upstream of EIF3D) recapitulated the effects of EIF3D knockdown in vitro, but not in vivo. Collectively, this study represents a comprehensive analysis of NMIBC and MIBC providing a resource for future studies. The results highlight EIF3D as a potential therapeutic target.

\section{INTRODUCTION}

Bladder Cancer $(\mathrm{BC})$ is the second most frequently reported malignancy of the genitourinary system, with an estimate of 429,800 new cases and 165,100 deaths in 2012 $[1,2]$. Based on the penetration depth into the bladder wall, $70 \%$ of the newly diagnosed tumors are classified as non-muscle invasive bladder cancer (NMIBC, stages $\mathrm{pTa}, \mathrm{pT} 1, \mathrm{pTis}$ ) and are treated by transurethral resection and intravesical therapies [3]; whereas the remaining 30\% are categorized as muscle invasive bladder cancer (MIBC, stages pT2-4) and are treated by radical cystectomy, 
(neo)adjuvant chemotherapy or (chemo) radiotherapy [4-6]. Patients harboring MIBC are associated with poor outcome: when the cancer is diagnosed at a localized stage (cancer has not spread beyond the bladder wall), the 5-year survival rate is $47 \%$ for patients with muscle-invasive disease in comparison to $81 \%$ in the case of non-muscle invasive disease [7]. Considering the severity of the disease, some novel therapies are currently investigated in clinical trials, including cancer immunotherapies targeting proteins such as programmed cell death protein 1 (PD-1), cytotoxic T-Lymphocyte associated protein 4 (CTLA-4) [8]; cell cycle checkpoint inhibitors targeting Aurora kinase A [9] and signal transduction inhibitors targeting fibroblast growth factor receptors (FGFR) [10].

To date, extensive efforts have been made to characterize the molecular background of BC [11]. Early efforts in the interpretation of $\mathrm{BC}$ molecular profiling data recapitulated a dual-track model, which proposes that the disease develops via two distinct forms $[12,13]$. The papillary NMIBCs originate from urothelial hyperplasia as a result of the alteration of the phosphatidylinositol 3-kinase (PI3K)- protein kinase B (Akt)-mTOR (PI3KAKT-mTOR) pathway, mutations in FGFR3 and HRas proto-oncogene [14]. On the other hand, the non-papillary MIBCs are developing from flat dysplasia and carcinoma in situ (CIS) and are characterized by genetic alterations in tumor suppressor genes such as tumor protein p53 (TP53), cyclin dependent kinase inhibitor 2A (CDKN2A), Cyclin D1 (CCND1), cyclin dependent kinase inhibitor 1B (CDKN1B) and RB transcriptional corepressor 1 (RB1) [14]. Although, this model explains many features of BC, it does not adequately address the heterogeneity of the disease [13]. Emerging evidence from next-generation sequencing data, mainly from MIBC, indicates its high phenotypic diversity and sub-clonal cancer evolution [11, 15-20]. Consequently, the presence of distinct molecular disease subtypes have been suggested by various groups (as summarized in [19, 21]) opening up new research avenues towards better patient stratification and tailored therapy selection [22].

Investigations at the protein level are attractive, since proteins manifest the functional state of the diseaserelated molecular alterations and are direct targets for pharmaceutical intervention [23]. Tissue samples represent the site of cancer initiation and progression and, therefore, serve as a very appropriate biological source for studying disease-associated alterations. Currently, there is a growing number of studies exploring $\mathrm{BC}$ tissue specimens using proteomics techniques [24-34]. Over the past years, emphasis has been placed on investigating the differences between $\mathrm{BC}$ and the adjacent normal urothelial tissue or non-cancerous specimens. As a result of these studies, novel biomarkers for cancer diagnosis [e.g. stathmin 1 (STMN1), transgelin 2 (TAGLN2) [25]] or potential targets for therapeutic intervention were proposed (e.g. phosphoglycerate mutase 1 (PGAM1) [24]).
Furthermore, efforts have been made towards the proteomic characterization of individual profiles of NMIBC and MIBC $[27,31,32,34]$, in the context of both cellular and stromal changes. For example, comparative proteomic analysis of non-muscle invasive cancer cells and normal urothelial cells revealed changes in pathways related to oxidative phosphorylation, focal adhesion, ribosome biogenesis, and leukocyte transendothelial migration [31]. In a followup study, proteomic characterization of NMIBC was performed, aiming at the investigation of cellular (purified normal urothelial cells versus non-muscle invasive cancer cells) and stromal changes (normal stromal cells versus non-muscle invasive cancer stromal cells) [27]. Alteration of several pathways was predicted including metabolic pathways, endocytosis, oxidative phosphorylation, and spliceosome function [27]. In another study, Niu et al. performed a global characterization of the stromal proteome of MIBC [32]. Pathway analysis of differentially expressed proteins between cancer and normal stromal cells indicated changes in metabolic pathways, actin cytoskeleton remodeling, adhesion, and endocytosis [32]. Changes in focal adhesion and extracellular matrix (ECM)-receptor interaction, based on analysis of stromal cells from MIBC were associated with the risk of cancer metastasis [34].

A comprehensive, high resolution, direct comparison of tissue proteomic profiles between NMIBC and MIBC has not been performed yet, to the best of our knowledge. Moreover, using the tissue adjacent to the tumor as normal control might not be an optimal experimental set up to discover what molecular changes make $\mathrm{BC}$ aggressive, as these areas have frequently cancer-related genetic characteristics [35]. Therefore, when aiming at the investigation of the molecular events underlying disease progression and subsequently key molecules that could also be "druggable" targets for therapeutic intervention, evaluation of tissue specimens that represent different stages of disease appears to be well justified.

The main objective of this study was the global characterization of the proteomic changes underlying $\mathrm{BC}$ invasion that could ultimately lead to a better understanding of disease pathophysiology and subsequent identification of biology-driven therapeutic targets. Towards that end, a comparative proteomic analysis of tissue specimens from NMIBC and MIBC was conducted. In silico analysis of differentially expressed proteins predicted, among others, a significant up-regulation of protein synthesis. By using in vitro assays and in vivo models, the functional relevance of eukaryotic translation initiation factor 3 subunit D (EIF3D) was evaluated in detail.

\section{RESULTS}

\section{Tissue proteomic profiling}

Untargeted proteome analysis of $\mathrm{BC}$ tissue specimens (NMIBC; $\mathrm{pTa}, n=5$ versus $\mathrm{MIBC} \mathrm{pT} 2+n=6$ ) 
was performed using high resolution liquid chromatography coupled to tandem mass spectrometry (LC-MS/MS) analysis in combination with two different software packages for protein identification and quantification, in order to maximize the reliability of differential protein expression analysis (workflow presented in Figure 1). As shown (Figure 1), comparable numbers of proteins were identified in the experimental groups (pTa and pT2+) by both software packages (Proteome Discoverer, PD, and Trans Proteomic Pipeline, TPP). To increase the reliability of the subsequent differential expression analysis, only proteins detected in $\geq 60 \%$ of specimens $(3 / 5$ for $\mathrm{pTa}$ and $4 / 6$ for pT2+) in at least one group (pTa, pT2+) were considered further. Proteins were defined as differentially expressed between the two groups based on statistical significance ( $p<0.05$, independent sample $t$-test; Figure 1). As depicted in Figure 1, sixty proteins were statistically significant according to both approaches (PD and TPP) and were considered of high validity and reliability. Thus, for these proteins thorough literature mining was performed to identify novel proteins associated with $\mathrm{BC}$ invasion (listed in Supplementary Table 1). Numerous proteins previously associated with BC were part of this list including, but not limited to hydroxyprostaglandin dehydrogenase 15-(NAD) (HPGD) [36], thymidine phosphorylase (TYMP) [37], annexins (e.g. ANXA1 [38], ANXA5 [39], ANXA10 [40]), alpha actinins (ACTN) (e.g. ACTN1 [41], ACTN4 [42, 43]), membrane-associated progesterone receptor component 1 (PGRMC1) [44], transforming growth factor-beta-induced protein ig-h3 (TGFBI) [45], cadherin 13 (CDH13) [46], or cathepsin E (CTSE) [47], serving as a positive control for the performed study. In addition, proteins that have been related to other cancers but not to BC yet, were also identified, such as fibulin-2 (FBLN2), tissue alpha-L-fucosidase (FUCA1), staphylococcal nuclease domain-containing protein 1 (SND1), and EIF3D. Importantly, we also identified differentially expressed proteins not yet described in $\mathrm{BC}$ or other types of malignancy, such as BRO1 domaincontaining protein BROX (BROX), vesicle-trafficking protein SEC22b (SEC22B), RNA 3'-terminal phosphate cyclase (RTCA) (described below in more detail). A detailed categorization of the proteomics findings with the representative references supporting their grouping is presented in Supplementary Table 1. We subsequently performed validation of the differential expression of some of the proteins that had not been previously linked to $\mathrm{BC}$ or $\mathrm{BC}$ tissue using immunohistochemistry analysis of a small, yet new (e.g. not used for the proteomic analysis) set of tissue samples. Based on appropriate antibody availability (as confirmed by using Western blot, data not shown), the difference in the expression level between MIBC and NMIBC could be confirmed for FUCA1, BROX, PGRMC1 and $26 \mathrm{~S}$ proteasome non-ATPase regulatory subunit 12 (PSMD12). As shown in Figure 2, in agreement with the proteomics results, a decline in the expression levels of the former 3 proteins in invasive versus noninvasive cancers could be observed, reaching statistical significance in the case of BROX, and FUCA1, whereas a statistically significant up-regulation was observed in the case of PSMD12.

\section{Assessment of biological relevance of proteomics findings}

To assess the biological relevance of the observed molecular changes in BC invasion and predict potentially new targets, in silico pathway and interactome analyses of the differentially expressed proteins was performed. To maximize coverage, the list of 60 proteins was expanded to include proteins found to be differentially expressed (statistically significant) by one quantification strategy and characterized by the same expression trend (up- or downregulation and at least 1.5 fold change) in the second. Applying these criteria, 144 proteins were identified as differentially regulated between the two groups (Supplementary Table 2; full datasets per quantification approach are available in Supplementary Table 3). Seventy-three out of the 144 proteins were mapped to 208 pathways, 52 of which were predicted to be significantly altered ( $p<0.05$, right-tailed Fisher Exact Test) in MIBC. Pathways with at least 3 molecules assigned were prioritized according to the significance level $(p<0.05)$ and the top 20 findings are presented in Table 1. These included pathways related to protein synthesis [i.e. eukaryotic initiation factor 2 (eIF2) signaling, mammalian target of rapamycin kinase (mTOR) signaling, tRNA charging, regulation of eukaryotic initiation factor 4 (eIF4) and ribosomal protein S6 kinase beta-1 (p70S6K) signaling], endocytosis (i.e. caveolar and clathrin-mediated endocytosis signaling), cell-ECM interactions, cytoskeletal remodeling, cell adhesion (i.e. integrin signaling, actin cytoskeleton signaling, paxillin signaling, remodeling of epithelial adherens junctions, epithelial adherens junction signaling), oxidative response / xenobiotic metabolism [nuclear factor, erythroid 2 like 2 (NRF2)mediated oxidative stress response, glutathione-mediated detoxification, aryl hydrocarbon receptor signaling], and angiogenesis [vascular endothelial growth factor (VEGF) signaling]. High consistency in the expression trend (up-/ down-regulation in MIBC versus NMIBC) of molecules mapped to the pathways was most evident for pathways targeting protein synthesis including eIF2 signaling, tRNA charging, regulation of eIF4 and p70S6K, as well as mTOR signaling (Table 1). All proteins mapped to these pathways were up-regulated in MIBC, with an exception of 5'-AMPactivated protein kinase subunit gamma-2 (PRKAG2) which was down-regulated in MIBC. However, the downregulation of PRKAG2 is expected, when the mTOR pathway is activated [48] (Supplementary Figure 1).

A parallel analysis of predicted protein-protein interactions revealed that 97 out of the aforementioned 
Table 1: The top 20 pathways, with at least 3 molecules assigned, predicted based on proteomics data

\begin{tabular}{|c|c|c|c|c|c|}
\hline \multirow[b]{2}{*}{ Pathway } & \multirow[b]{2}{*}{$p$-value } & \multirow[b]{2}{*}{$\begin{array}{l}\text { \# associated } \\
\text { molecules }\end{array}$} & \multirow[b]{2}{*}{$\begin{array}{c}\text { Pathway Activation } \\
\text { (z-score) }\end{array}$} & \multicolumn{2}{|c|}{ Molecules } \\
\hline & & & & Up-regulated in MIBC & $\begin{array}{c}\text { Down-regulated in } \\
\text { MIBC }\end{array}$ \\
\hline \multicolumn{6}{|l|}{ Protein synthesis-related pathways: } \\
\hline EIF2 Signaling & $6.9 \mathrm{E}-07$ & $10 / 185$ & Activated (2.24) & $\begin{array}{l}\text { RPL12, RPS13, EIF3D, RPS9, } \\
\text { RPS18, RPL22, RPL31, RPS14, } \\
\text { RPL27A, RPL10A }\end{array}$ & \\
\hline tRNA Charging & $2.5 \mathrm{E}-03$ & $3 / 39$ & & TARS, VARS, WARS & \\
\hline $\begin{array}{l}\text { Regulation of eIF4 and p70S6K } \\
\text { Signaling }\end{array}$ & $3.6 \mathrm{E}-03$ & $5 / 146$ & & $\begin{array}{l}\text { RPS13, EIF3D, RPS9, RPS18, } \\
\text { RPS14 }\end{array}$ & \\
\hline mTOR Signaling & $2.0 \mathrm{E}-03$ & $6 / 188$ & & $\begin{array}{l}\text { RPS13, EIF3D, RPS9, RPS18, } \\
\text { RPS14 }\end{array}$ & PRKAG2 \\
\hline \multicolumn{6}{|c|}{ Oxidative response/xenobiotic metabolism -related pathways: } \\
\hline $\begin{array}{l}\text { NRF2-mediated Oxidative } \\
\text { Stress Response }\end{array}$ & $5.5 \mathrm{E}-07$ & $10 / 180$ & Activated (1.00) & EPHX1, FTL, PPIB, ACTG2 & $\begin{array}{l}\text { GSTM1, GSTM5, UBB, } \\
\text { GSTM2, GSTM3, GSTM4 }\end{array}$ \\
\hline $\begin{array}{l}\text { Glutathione-mediated } \\
\text { Detoxification }\end{array}$ & $1.9 \mathrm{E}-06$ & $5 / 30$ & & & $\begin{array}{l}\text { GSTM1, GSTM5, GSTM2, } \\
\text { GSTM3, GSTM4 }\end{array}$ \\
\hline $\begin{array}{l}\text { Aryl Hydrocarbon Receptor } \\
\text { Signaling }\end{array}$ & $5.8 \mathrm{E}-05$ & $7 / 140$ & & & $\begin{array}{l}\text { SRC, GSTM1, GSTM5, } \\
\text { GSTM2, GSTM3, GSTM4, } \\
\text { NEDD8 }\end{array}$ \\
\hline \multicolumn{6}{|l|}{ Endocytosis-related pathways: } \\
\hline $\begin{array}{l}\text { Caveolar-mediated Endocytosis } \\
\text { Signaling }\end{array}$ & $1.6 \mathrm{E}-03$ & $4 / 72$ & & COPA, COPG1, ACTG2 & SRC \\
\hline $\begin{array}{l}\text { Clathrin-mediated Endocytosis } \\
\text { Signaling }\end{array}$ & $1.9 \mathrm{E}-03$ & $6 / 185$ & & ARPC2, AP2A1, ACTG2 & UBB, SRC, CD2AP \\
\hline \multicolumn{6}{|c|}{ Cell-ECM interactions, cytoskeletal remodeling, cell adhesion -related pathways: } \\
\hline $\begin{array}{l}\text { Remodeling of Epithelial } \\
\text { Adherens Junctions }\end{array}$ & $7.9 \mathrm{E}-06$ & $6 / 68$ & & $\begin{array}{l}\text { ARPC2, ACTN2, ACTN1, ACTN4, } \\
\text { ACTG2 }\end{array}$ & $\mathrm{SRC}$ \\
\hline $\begin{array}{l}\text { Epithelial Adherens Junction } \\
\text { Signaling }\end{array}$ & 7.4E-05 & $7 / 146$ & & $\begin{array}{l}\text { ARPC2,ACTN2, MYH10, ACTN1, } \\
\text { ACTN4, ACTG2 }\end{array}$ & $\mathrm{SRC}$ \\
\hline Integrin Signaling & 8.7E-05 & $8 / 202$ & Activated (2.12) & $\begin{array}{l}\text { ARPC2,MYLK, ACTN2, ACTN1, } \\
\text { ACTN4, ACTG2 }\end{array}$ & SRC, VASP \\
\hline Actin Cytoskeleton Signaling & $1.4 \mathrm{E}-04$ & $8 / 217$ & & $\begin{array}{l}\text { ARPC2, GSN, MYLK, ACTN2, } \\
\text { MYH10, ACTN1, ACTN4, ACTG2 }\end{array}$ & \\
\hline Paxillin Signaling & 7.4E-04 & $5 / 102$ & Activated (1.34) & ACTN2, ACTN1, ACTN4, ACTG2 & SRC \\
\hline $\begin{array}{l}\text { Regulation of Cellular } \\
\text { Mechanics by Calpain Protease }\end{array}$ & $6.8 \mathrm{E}-04$ & $4 / 57$ & & ACTN2, ACTN1, ACTN4 & $\mathrm{SRC}$ \\
\hline \multicolumn{6}{|l|}{ Angiogenesis -related pathways: } \\
\hline VEGF Signaling & $4.4 \mathrm{E}-04$ & $5 / 91$ & Activated (1.34) & ACTN2, ACTN1, ACTN4, ACTG2 & SRC \\
\hline \multicolumn{6}{|l|}{ Other pathways: } \\
\hline $\begin{array}{l}\text { Leukocyte Extravasation } \\
\text { Signaling }\end{array}$ & $4.8 \mathrm{E}-04$ & $7 / 198$ & Activated (1.89) & $\begin{array}{l}\text { ACTN2, ACTN1, ACTN4, GNAI3, } \\
\text { ACTG2 }\end{array}$ & SRC, VASP \\
\hline $\begin{array}{l}\text { Germ Cell-Sertoli Cell Junction } \\
\text { Signaling }\end{array}$ & $9.1 \mathrm{E}-04$ & $6 / 160$ & & $\begin{array}{l}\text { GSN, ACTN2, ACTN1, ACTN4, } \\
\text { ACTG2 }\end{array}$ & SRC \\
\hline $\begin{array}{l}\text { Sertoli Cell-Sertoli Cell Junction } \\
\text { Signaling }\end{array}$ & $1.5 \mathrm{E}-03$ & $6 / 178$ & & ACTN2, ACTN1, ACTN4, ACTG2 & SRC, PRKAG2 \\
\hline Protein Ubiquitination Pathway & 7.6E- 05 & $9 / 255$ & & $\begin{array}{l}\text { PSMD12, PSMA7,PSMA2,PSMB2, } \\
\text { PSMB3, UBE2D3 }\end{array}$ & UBB,UCHL3, HSPE1 \\
\hline
\end{tabular}

The findings were prioritized based on the significance level and number of associated proteins ( $\geq 3$ ). The latter's (e.g. associated proteins) trend of expression (up- or downregulated) in MIBC versus NMIBC is indicated. Pathways were generated through the use of QIAGEN's Ingenuity Pathway Analysis (IPA ${ }^{\circledR}$, QIAGEN Redwood City, www. qiagen.com/ingenuity).

144 proteins are involved in an interactome network (261 interactions were retrieved), as shown in Figure 3. In line with the pathway analysis, multiple proteins associated with the interactome network create functional clusters related to protein synthesis (e.g. EIF3D, numerous ribosomal subunits), protein degradation [e.g. polyubiquitin-B (UBB), enzymes such as ubiquitin carboxyl-terminal hydrolase isozyme L3 (UCHL3), ubiquitin-conjugating enzyme E2 D3 (UBE2D3), numerous subunits of proteasome], glutathione detoxification (e.g. glutathione transferases), 
metabolism [e.g. enzymes such as UTP--glucose-1phosphate uridylyltransferase (UGP2), glucose-6phosphate 1-dehydrogenase (G6PD), bisphosphoglycerate mutase (BPGM)] and endocytosis (e.g. SEC22B, subunits of coatamer, Protein ERGIC-53). Of note, many of the proteins (36 out of the 97 ) that were included in the interactome network were not mapped to pathways. This includes proteins that have not been previously investigated

\section{LC-MS/MS analysis \\ $\operatorname{pTa}(n=5) \downarrow p T 2+(n=6)$}

Data analysis \& Quantification

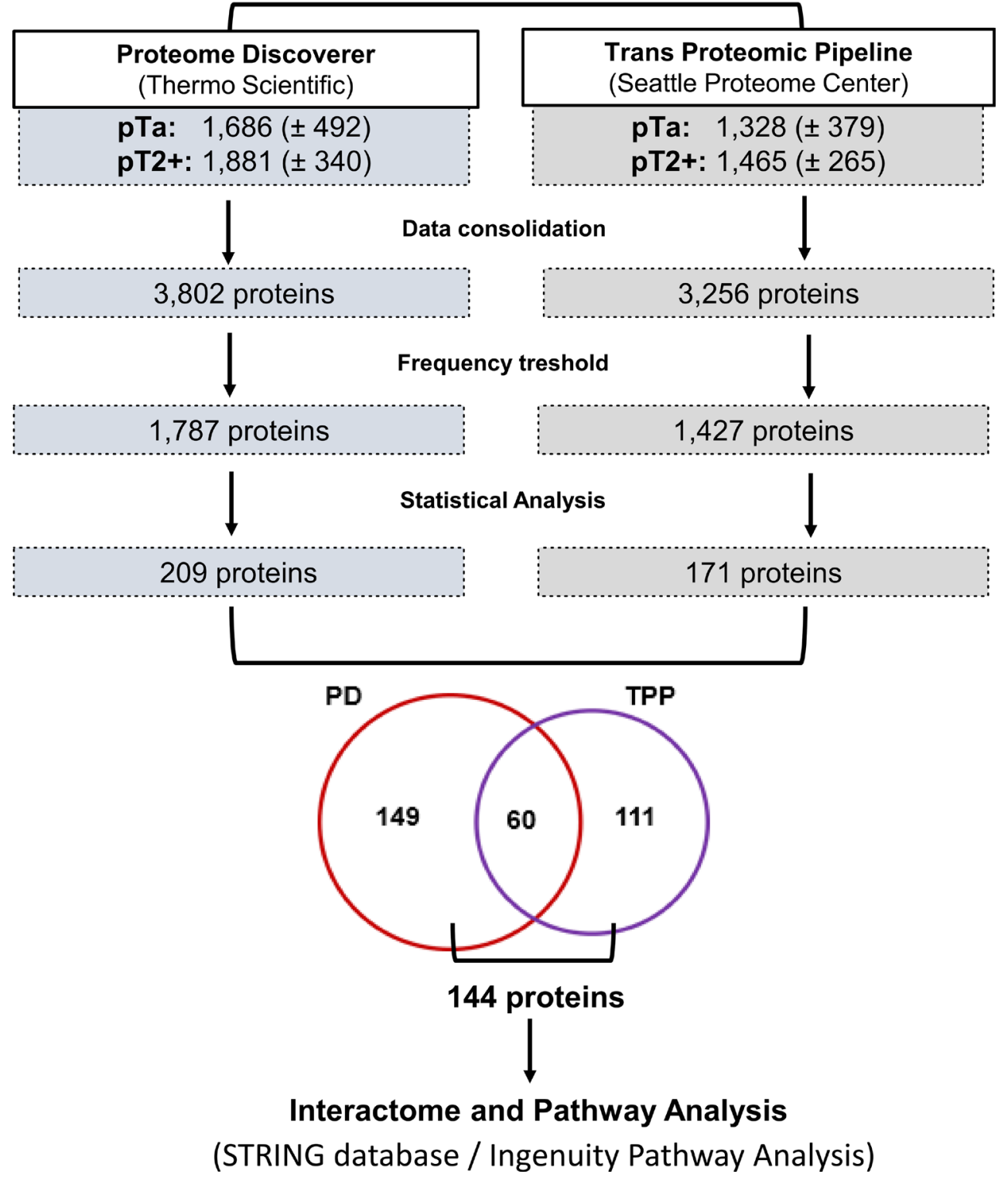

Figure 1: Schematic representation of the MS data analysis workflow. A total of 11 bladder cancer tissue proteomic profiles were generated and analyzed using two independent approaches. This includes analysis using Proteome Discoverer and Trans Proteomic Pipeline followed by quantification based on peak area and spectral counting (i.e. APEX), respectively. Following consolidation of the individual proteomics profiles, proteins identified in at least $60 \%$ of samples of at least one group $(\mathrm{pTa} / \mathrm{pT} 2+)$ were considered in differential expression analysis. For those, statistical analysis was performed to identify disease-associated proteins $(p<0.05)$. A total of 60 proteins were found to be significantly altered according to both approaches. The overlap increases to 144 proteins, when considering proteins found to be differentially expressed (statistically significant level) by at least one approach and exhibiting the same regulation trend based on the other quantification approach (up/down-regulation by at least 1.5 fold). These latter 144 proteins were further analyzed by pathway and interactome approaches. 
A

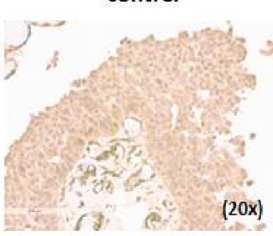

(ii) PGRMC1

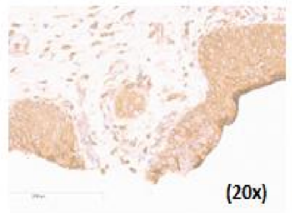

(iii) BROX

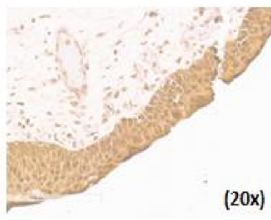

(iv) PSMD12

(20x)
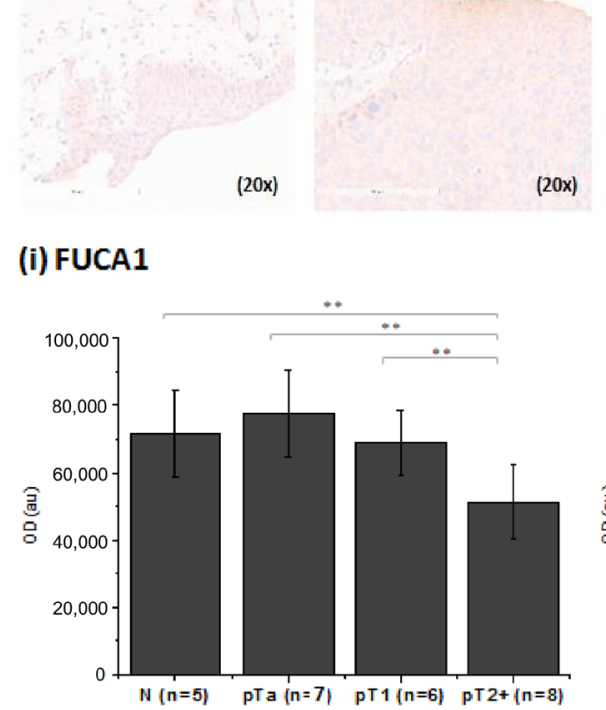

pT1
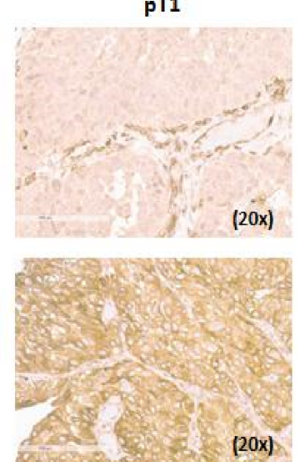

(20x)

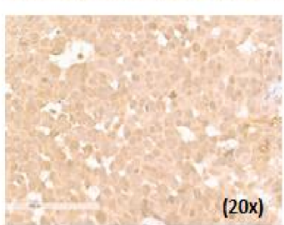

(20x)

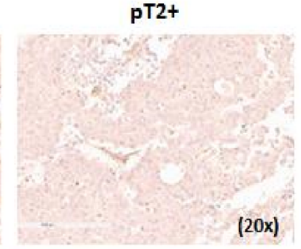

(20x)
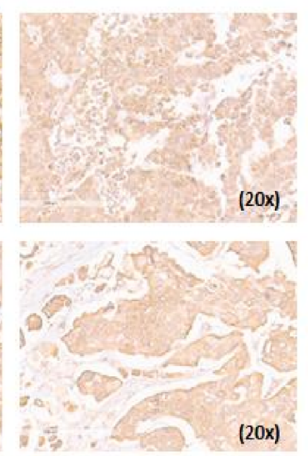

(20x)

(20x)

(20x) (i) FUCA1

(iii) BROX

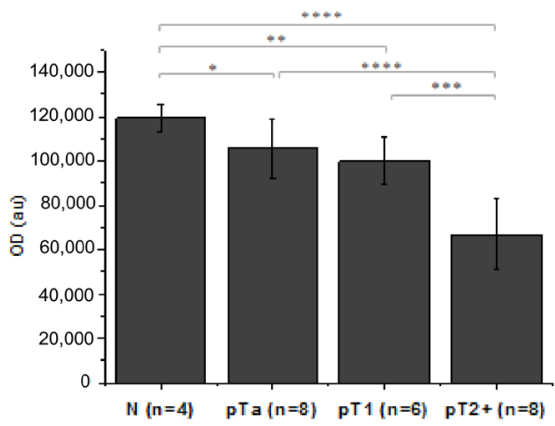

B

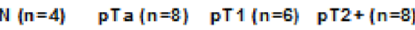

\section{(ii) PGRMC1}

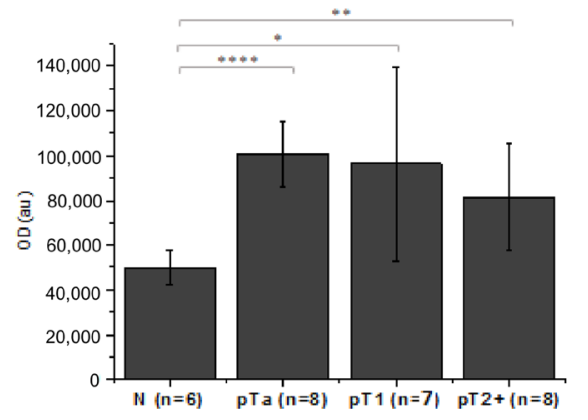

(iv) PSMD12

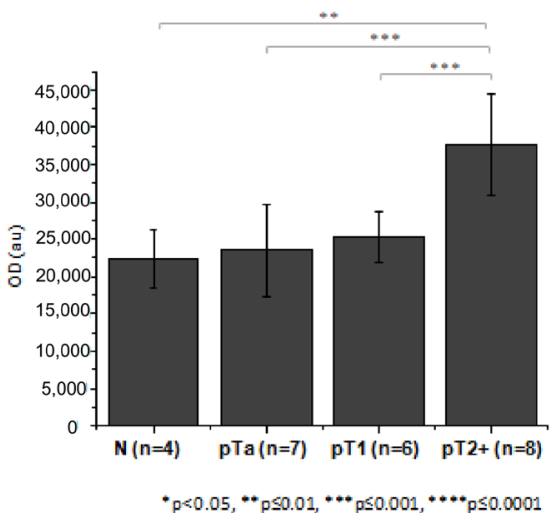

Figure 2: Verification of proteomics findings using immunohistochemistry. (A) Stained sections and (B) quantification results for (i) FUCA 1, (ii) PGRMC1 (iii) BROX and (iv) PSMD12 from control, pTa, pT1 and pT2+ human samples are presented. Immunohistochemistry analysis was performed using tissue microarrays (total $n=30$ including 6 controls, $8 \mathrm{pTa}, 8 \mathrm{pT} 1,8 \mathrm{pT} 2+$ ). For each protein, the exact number of tissue sections included for the quantification is presented in the figure. Quantification of the staining intensity was performed using the Image J software. Mean staining intensities and standard deviations per analyzed group are presented. Statistical analysis was performed using an independent sample $t$-test. 
in BC tissue specimens, such as FUCA1, PGRMC1 and PSMD12 [confirmed by immunohistochemistry (IHC) as detailed above], but also trans-Golgi network integral membrane protein 2 (TGOLN2), transmembrane glycoprotein NMB (GPNMB), and TGFBI.

Collectively, the molecular processes (the aforementioned: protein synthesis, degradation, glutathione detoxification etc., shown in Table 1) were further shortlisted based on their predicted activation score (z-score using Ingenuity Pathway Analysis), significance level and agreement in the fold change direction of protein findings mapped to these pathways. Among the top 20 shortlisted pathways (based on the significance level), eIF2 signaling (ranked as $2^{\text {nd }}$ based on the significance level) was characterized by the highest activation z-score. Additionally, all detected proteins involved in this pathway were up-regulated in MIBC versus NMIBC. Interestingly, eIF2 signaling partially overlaps with the mTOR pathway, which is under investigation in the context of $\mathrm{BC}$, with mTOR inhibitors being tested as potential targets for $\mathrm{BC}$ therapeutic intervention [49]. Given, in addition, the existing interest on protein synthesis as a source of promising anticancer drugs [50], we shortlisted pathways related to protein synthesis for further investigation, focusing on eIF2 and mTOR signaling. Among the proteins indicated by the tissue proteomic analysis, EIF3D, not earlier associated with BC, was overexpressed in MIBC versus NMIBC (Supplementary Figure 2) and was selected as candidate for further investigation.

\section{Lentivirus-mediated RNAi knockdown of EIF3D in $\mathrm{T} 24 \mathrm{M}$ cells}

In order to investigate the therapeutic impact of EIF3D in BC progression, we performed its stable knockdown through lentivirus-mediated RNA interference, in the metastatic T24M BC cell line (given that enhanced expression of this protein was observed in MIBC). T24M cells were transduced with the shEIF3D lentivirus, while shscramble lentivirus-transduced and/or untransduced T24M cells were used as controls. The knockdown efficiency was assessed 4 days after the transduction at the RNA level by real-time PCR and at the protein level by Western blot analysis. As shown in Figure 4, EIF3D expression was significantly reduced at the mRNA level by $82 \% \pm 10 \%$ in T24M shEIF3D cells compared to T24M cells shscramble ( $p \leq 0.001$, Student's $t$-test) and at the protein level by $64.6 \% \pm 2.46 \%$, respectively ( $p \leq 0.01$, Student's $t$-test). No significant differences were detected between T24M shscramble and T24M untransduced cells

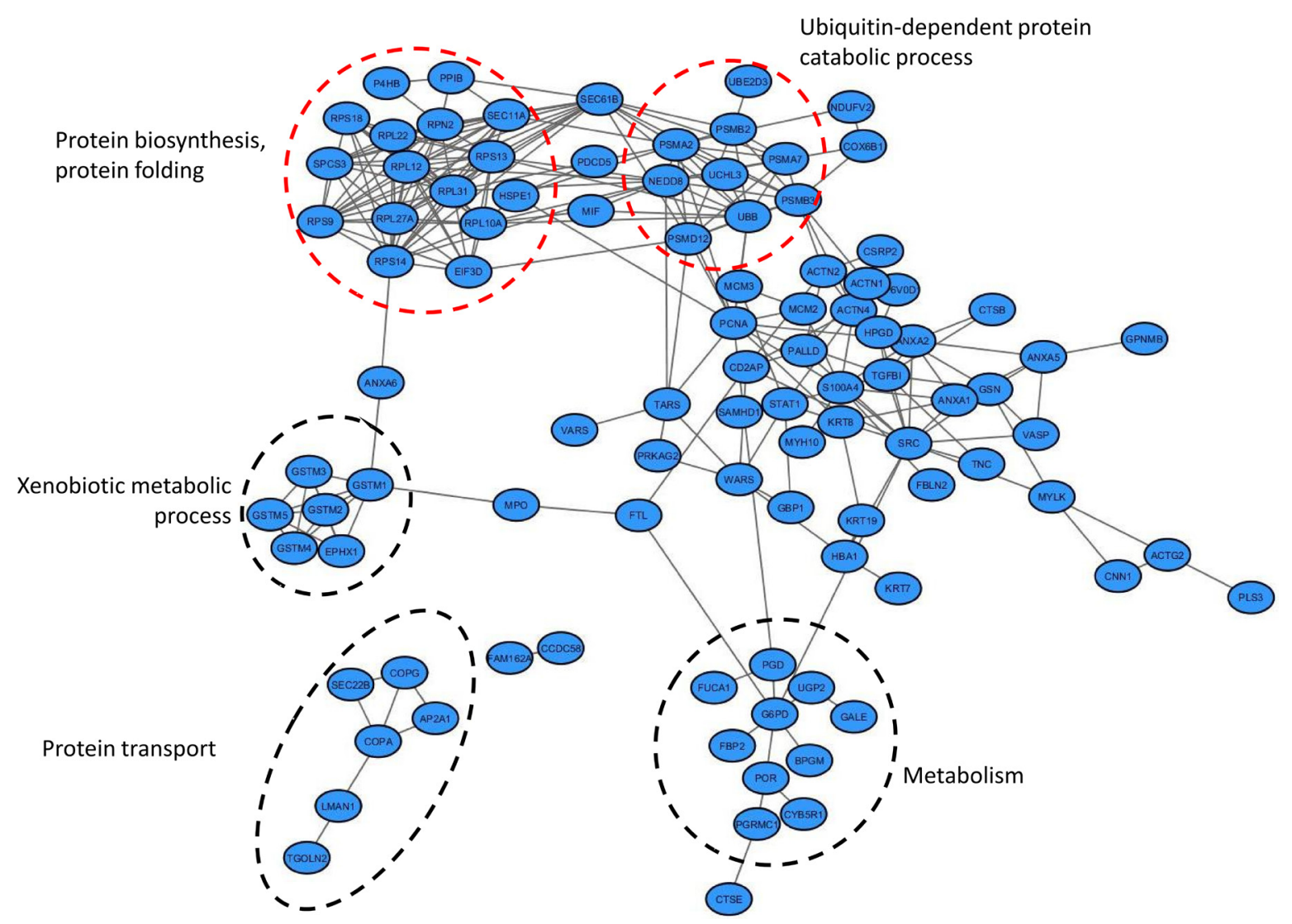

Figure 3: Interactome network of proteins altered during bladder cancer invasion. Functional annotations of the proteins included in the interaction network was conducted using Gene Ontology Annotation (UniProt-GOA) Database [123]. Proteins involved in protein degradation/protein synthesis clusters are marked in red circles. 
either at the EIF3D RNA or at the protein level ( $p>0.05$, Student's $t$-test).

\section{EIF3D knockdown attenuates the tumorigenic properties of $\mathrm{T} 24 \mathrm{M}$ cells}

To elucidate the possible impact of EIF3D on BC, we further investigated the impact of its knockdown onto the malignant phenotype of T24M cells, including impact on cell proliferation, migration and colony forming ability in vitro and tumor growth in NOD/SCID T24M xenografts. As shown in Figure 5A, the stable knockdown of EIF3D in T24M cells resulted in a 63\% decreased proliferation rate compared to $\mathrm{T} 24 \mathrm{M}$ shscramble cells after culture for 3 days $(0.282 \pm 0.115$ au versus $0.543 \pm 0.058$ au; $p \leq 0.0001$, Student's $t$-test) and in a $51 \%$ decrease after 4 days $(0.367 \pm 0.133$ au versus $0.617 \pm 0.034 \mathrm{au}$; $p \leq 0.0001$, Student's $t$-test), respectively. The data from both time points were normalized to the measurements from day $0(0.139 \pm 0.010$ au for T24M shscramble and $0.133 \pm 0.007$ au for T24M shEIF3D). No significant difference was observed between T24M shscramble and T24M untransduced cells. A significant reduction was also observed in the migratory capacity of T24M cells towards their conditioned media (CM) following EIF3D knockdown compared to T24M shscramble cells $(80 \pm 19$ cells versus $164 \pm 21$ cells; $p \leq 0.001$, Student's $t$-test),

\section{RNA level}

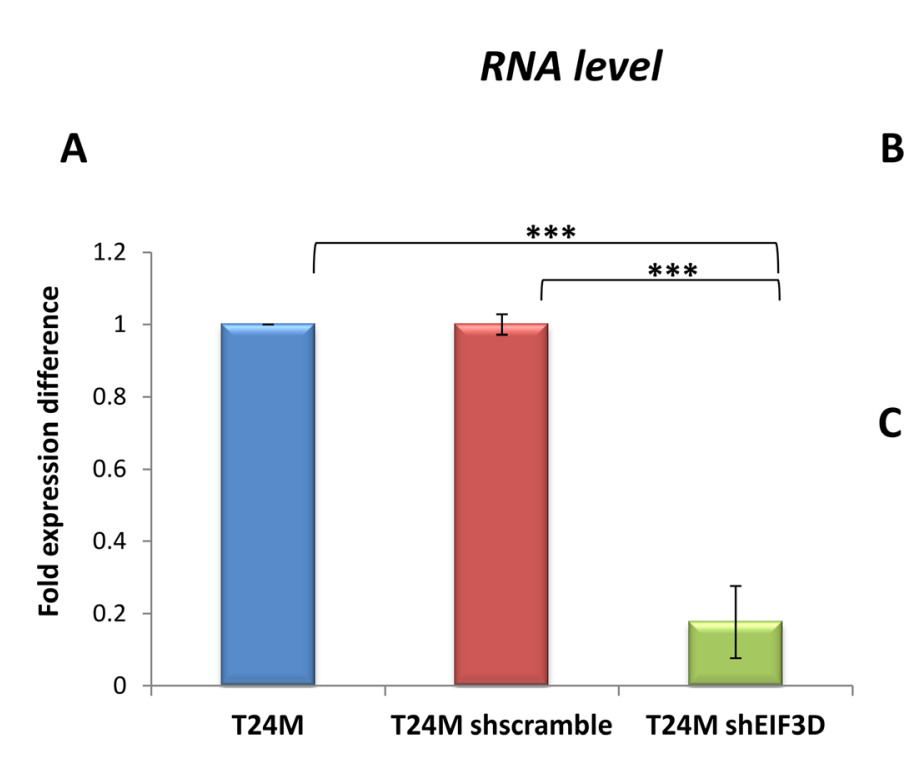

(Figure 5B), whereas, no significant difference in the migration of T24M shscramble and T24M untransduced cells was detected. With respect to T24M colony forming ability (Figure 5C), no significant difference in the number of colonies formed by T24M shEIF3D and T24M shscramble cells ( $23 \pm 2$ versus $22 \pm 3 ; p=0.86$, Student's $t$-test) was observed. Nevertheless, the diameter of the colonies was remarkably decreased in the former (56.459 \pm 10.965 pixels versus $100.362 \pm 17.516$ pixels; $p \leq 0.01$, Student's $t$-test), indicating impaired colony growth. These findings clearly indicate that EIF3D has a significant influence on the in vitro properties of T24M cells such as proliferation, migration and colony forming ability.

Based on these in vitro results, the impact of EIF3D knockdown was further investigated in vivo. T24M $(n=12)$, T24M shscramble $(n=12)$ and T24M shEIF3D $(n=14)$ tumor bearing mice were generated and examined for tumor growth over a period of at least 60 days. A significantly reduced tumor volume $\left(17.41 \pm 11.88 \mathrm{~mm}^{3}\right)$ was observed in the T24M shEIF3D mice compared to the T24M $\left(110.03 \pm 43.13 \mathrm{~mm}^{3} ; p \leq 0.0001\right.$, Student's $t$-test $)$ or the T24M shscramble $\left(98.32 \pm 50.59 \mathrm{~mm}^{3} ; p \leq 0.001\right.$, Student's $t$-test) tumor bearing mice (Figure 6A). The expression levels of EIF3D were further analysed in the excised tumors from all groups, 60 days after the injections, at the RNA level by real-time PCR and at the protein level by Western blot analyses. As shown

B

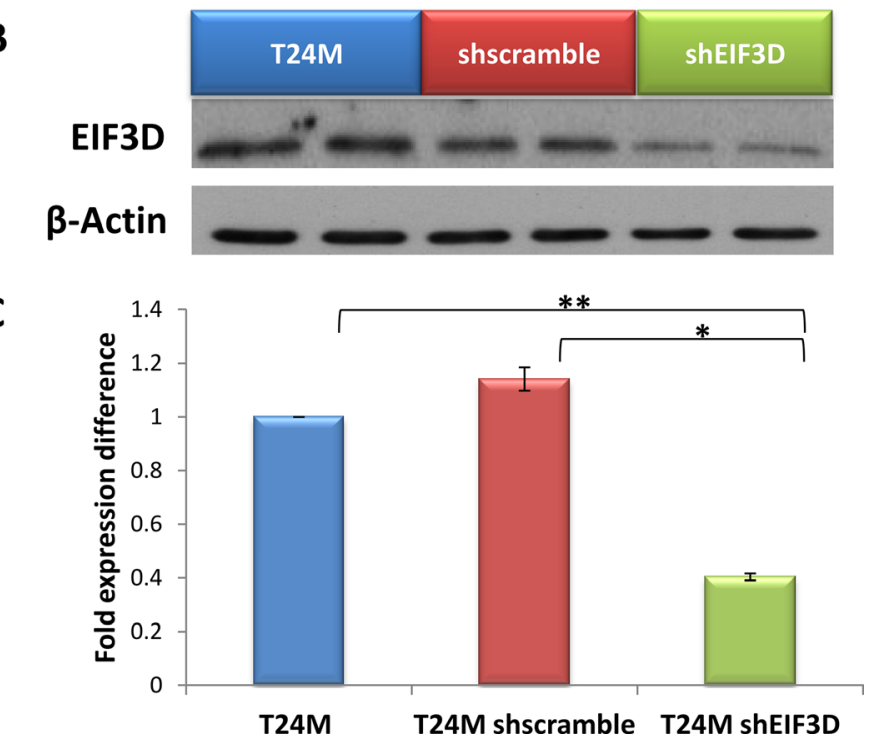

Figure 4: Evaluation of EIF3D knockdown in T24M cells at the RNA and protein level. (A) Bar graph representing the downregulation of EIF3D in T24M shEIF3D cells in comparison to T24M shscramble and untransduced T24M cells analysed by real-time PCR. The data were normalized to the human GAPDH reference gene and then to the control T24M untransduced cells. (B) Western blot analysis for EIF3D in cell extracts derived from T24M, T24M shscramble and T24M shEIF3D cells. (C) Bar chart showing data from the quantification analysis of EIF3D protein bands detected in T24M, T24M shscramble and T24M shEIF3D. The quantification of the proteins was performed by using the Quantity One software (BioRad) and the results were normalized to $\beta$-Actin loading control and then to the $\mathrm{T} 24 \mathrm{M}$ untransduced cells. The values represent the means \pm SD from three independent experiments performed in duplicate (two-tailed Student's $t$-test, $\left.{ }^{*} p \leq 0.05,{ }^{* *} p \leq 0.01, * * * p \leq 0.001\right)$. 
in Figure 6B, EIF3D was significantly reduced at the mRNA level by $45 \% \pm 2.6 \%$ in T24M shEIF3D compared to T24M shscramble tumors ( $p \leq 0.05$, Student's $t$-test) whereas no significant difference was observed between the T24M and the T24M shscramble tumors ( $p=0.39$, Student's $t$-test). Additionally, in another set of tumors the expression of EIF3D was examined at the protein level and, as illustrated in Figure 6C, it was found reduced by $92.78 \% \pm 6.74 \%$ in $\mathrm{T} 24 \mathrm{M}$ shEIF3D tumors compared to T24M shscramble ( $p \leq 0.01$, Student's $t$-test). No significant difference was detected between the T24M and the T24M shscramble tumors ( $p=0.33$, Student's $t$-test).

The specificity of the EIF3D findings was further supported by testing the impact of knock-down of an additional potential target selected from the pathway analysis: GTP-binding protein Rheb (RHEB), not previously associated with BC, laying upstream of EIF3D and considered one of the key molecules activating the
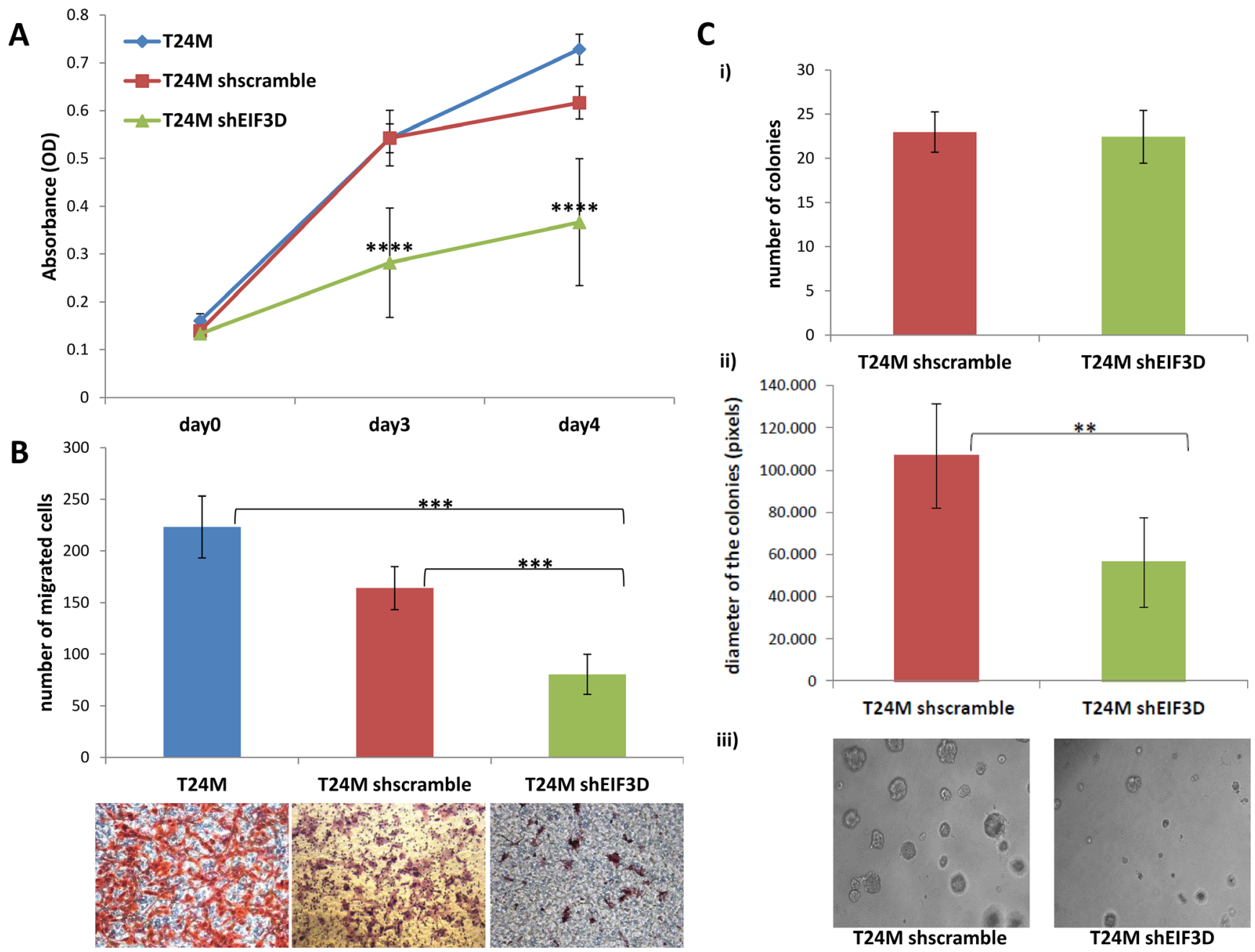

Figure 5: Impact of EIF3D downregulation on cell proliferation, migration and colony forming ability of T24M cells. (A) The knockdown of EIF3D significantly reduced the proliferation rate of T24M cells. The bar graph represents the proliferation rate of T24M, T24M shscramble and T24M shRHEB cells at three different time points (Day 0, Day 3, Day 4). The values represent the means \pm SD from three independent experiments performed in five replicates (two-tailed Student's $t$-test, $* * * * p \leq 0.0001$ ). (B) A significant reduction was also observed in the migratory capacity of T24M cells following EIF3D knockdown. The graph illustrates the number of cells migrated towards conditioned media derived from T24M cells. The cells were allowed to migrate for $6 \mathrm{~h}$ toward the CM. Representative images of the migrated cells from each condition are displayed below the graph. Magnification: $10 \times$. The values represent the means \pm SD from two independent experiments performed in duplicate (two-tailed Student's $t$-test, $* * * p \leq 0.001$ ). (C) The colony forming ability of T24M cells was significantly reduced in the case of EIF3D knockdown after 10 days of growth on matrigel. i) The bar graph illustrates the mean number of colonies formed by T24M shscramble and T24M shEIF3D cells. ii) Bar graph presenting the average diameter of the colonies formed by T24M shscramble and T24M shEIF3D cells. Although no significant difference in the number of colonies was detected, a remarkable decrease in the diameter of the colonies was observed upon to EIF3D knockdown. Colony diameters were measured by using ImageJ software and their length was given in pixels. iii) Representative images of the colonies formed by T24M shscramble and T24M shEIF3D cells. Magnification: 10x. The values represent the means \pm SD from two independent experiments performed in duplicate (twotailed Student's $t$-test, ${ }^{* *} p \leq 0.01$ ). 
mTOR complex ([51-54]; Supplementary Figure 1). In agreement with our predictions, RHEB was overexpressed in invasive versus non-invasive $\mathrm{BC}$ by Western blot analysis of a small set of tissue specimens (Supplementary Figure 3). However, while the lentivirus-mediated RNAi knockdown of RHEB (Supplementary Figure 4) decreased cell proliferation, migration and colony forming ability in vitro (Supplementary Figure 5), no impact on tumor growth in vivo was observable (Supplementary Figure 6).

\section{DISCUSSION}

The tissue proteome is a rich source of information about disease, as tissue is the site of disease initiation and progression (reviewed in [55]). In this study, we performed LC-MS/MS analysis of tissue specimens from NMIBC and $\mathrm{MIBC}$ in order to identify proteins significantly altered in MIBC and predict additional molecules and pathways altered during $\mathrm{BC}$ progression.
Considering the clinical relevance (limited treatment options for MIBC and associated significant decrease in the survival rate for patients that progress to MIBC), we focused our investigation on the comparative analysis between muscle-invasive (case group) and non-muscle invasive BC (control group). Inclusion of the nonmalignant tissue specimens in the proteomic analysis was not possible due to restricted sample availability, nevertheless this was performed during the more targeted IHC studies (Figure 2). By performing a comprehensive proteomic analysis, 144 proteins were found to be significantly differentially expressed between MIBC and NMIBC samples. Many of these proteins including annexin A10 (ANXA10) [40], HPGD [36], actinin alpha 4 (ACTN4) [42, 43], CTSE [47] and CDH13 [46] and a total of 21 others [including transforming growth factorbeta-induced protein ig-h3 (TGFBI), palladin (PALLD), adipogenesis regulatory factor (ADIRF), anterior gradient protein 2 homolog (AGR2), keratin type I cytoskeletal
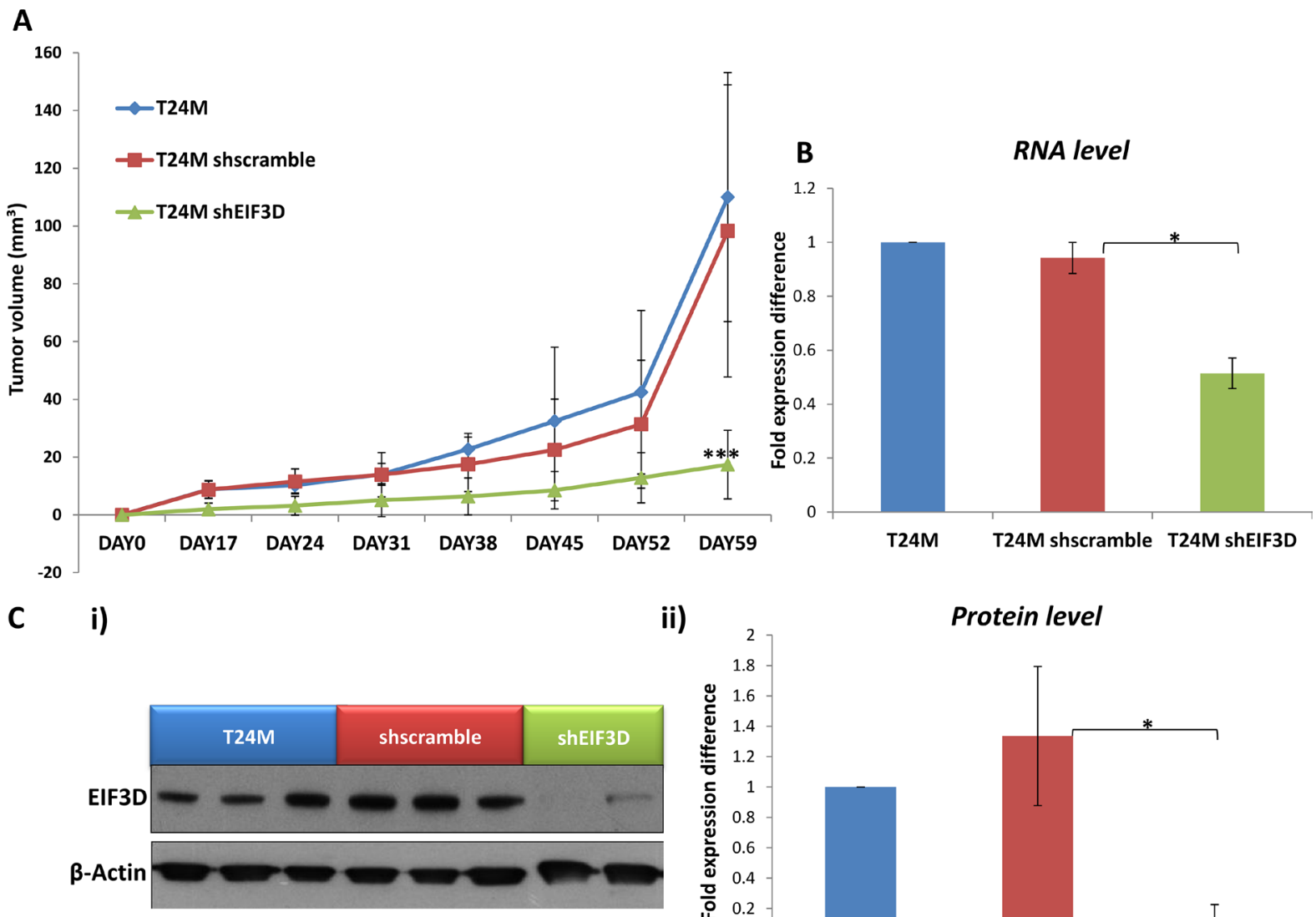

ii)

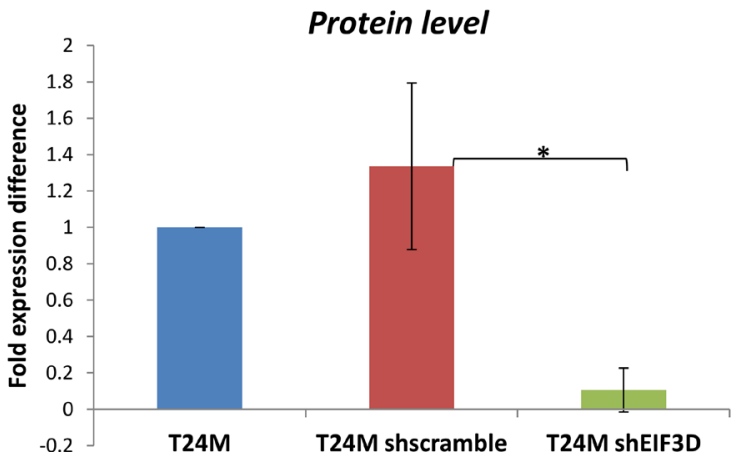

Figure 6: The knockdown of EIF3D impairs tumor growth in vivo. (A) Tumor growth in T24M, T24M shscramble and T24M shEIF3D tumor bearing NOD/SCID mice. Tumor volume was significantly smaller $(* * * p<0.01$, Student's $t$-test $)$ in T24MshEIF3D compared with T24M or T24M shscramble tumor bearing animals 59 days after the injections. (B) The expression of EIF3D was estimated in excised tumors from all groups of mice, 60 days after the injections, at the RNA level. Bar graph representing the downregulation of EIF3D in T24M shEIF3D tumors in comparison to T24M shscramble and T24M tumors analyzed with real-time PCR $\left({ }^{*} p<0.05\right.$, Student's $t$-test). (C) The knockdown of EIF3D in the tumors was also confirmed 60 days after the injections at the protein level. i) Western blot analysis for EIF3D in T24M, T24M shscramble and T24M shEIF3D tumors. ii) Bar chart showing the decreased levels of EIF3D in T24M shEIF3D tumors compared to T24M and T24M shscramble tumors ( ${ }^{*} p<0.05$, Student's $t$-test). 
19 (KRT19)] have already been associated with BC, when compared with a database on MIBC [56], serving as "positive controls" for the applied approach. Our results also revealed numerous proteins that have not been associated with or reported in BC tissue, including PGRMC1, FUCA1, BROX, coatomer protein complex subunit alpha (COPA), or threonyl-TRNA synthetase (TARS), with the differential expression of FUCA1, BROX, PGRMC1, and PSMD12 having been further confirmed in a small set of additional tumors by IHC. For the latter (PGRMC1), similar expression trends with a decrease in MIBC in comparison to NMIBC have also been observed in urine $[44,57]$. FUCA1 is a lysosomal enzyme responsible for removal of terminal L-fucose residues from oligosaccharide chains of glycosylated proteins [58]. It has been reported that treatment of highly invasive breast cancer cells (MDA MB 231) with alpha-Lfucosidase significantly decreases their invasive potential [59]. Additionally, adhesion of breast cancer cells to ECM components was reduced upon treatment with FUCA1 [60], supporting its inhibitory potential in cancer invasion (reviewed in [61]). In contrast to FUCA1, the biological function of BROX has not been elucidated yet [62-64]. The majority of proteins predicted to be a part of BROX interactome (based on STRING analysis) are components of the endosomal-sorting complex required for transport (ESCTR) system, which may suggest an involvement of this factor in sorting and recycling of growth factors. Finally, PSMD12 (also known as Rpn5), recently predicted to promote proliferation and metastasis based on network analysis [65], is a component of the multi-protein complex - 26 proteasome, involved in the ATP-dependent degradation of ubiquitinated proteins. Specifically, PSMD12 is one of the particles that builds the "lid" of the proteasome cap, with the latter being involved in the de-ubiquitination of targeted proteins (reviewed in [66]). Although, numerous inhibitors targeting the proteolytic activity of $26 \mathrm{~S}$ proteasome complex have been investigated as potential anti-tumor agents (reviewed in [67, 68]), the relevance of PSMD12 in cancer has not been investigated yet. It appears that further investigation of the biological relevance of these proteins in $\mathrm{BC}$ would be of interest.

An in-depth analysis of the proteomics findings revealed that a wide range of the aberrantly expressed proteins are involved in cancer hallmark processes such as cell cycle, proliferation, cell metabolism, apoptosis and furthermore in processes that are associated with cancer invasion, such as cytoskeleton remodeling, cell adhesion and migration. In silico analysis of the proteomics findings at pathway and interactome levels revealed an activation of protein synthesis pathways (eIF2 signaling, tRNA charging, regulation of eIF4 and p70S6K signaling and mTOR signaling), which have been previously reported to be deranged in the context of BC [69-79]. Collectively, these data enhance the validity of the proteomic analysis, and increase the credibility of the novel findings such as the observed decrease of FUCA1, BROX, PGRMC1 and increase of PSMD12 (also supported by the IHC analysis, Figure 2) in MIBC.

Given that protein synthesis pathways were clearly predicted to be activated in tumor growth and progression [80], they were more thoroughly investigated in order to better understand the contribution of individual proteins. Cancer cells are characterized by translational alterations that increase the rate of protein synthesis, sustaining in this way, cancer progression and survival [81-83]. One of the most complex and rate-limiting steps in this process is translation initiation, in which a great number of eukaryotic initiation factors are involved [84, 85]. Aberrant expression, mutations and post-translational modifications of many translation initiation factors have been previously described in different cancer types [50, 80]. Among the translation initiation factors, eukaryotic initiation factor 3 (eIF3) is the largest and most complex component. The human eIF3 translation initiation factor is an $800 \mathrm{kDa}$ complex that consists of 13 subunits and acts as a scaffold for the assembly of the initiation complex $[86,87]$. The aberrant expression of eIF3 subunits in different cancer types has been previously described in numerous studies [88]. In our study, EIF3D subunit was found to be up-regulated in MIBC compared to NMIBC and the knockdown of this factor resulted in the reduction of T24M cell proliferation, migration and colony forming ability in vitro, and decreased tumor growth in a xenograft mouse model in vivo. These findings are novel in the field of $\mathrm{BC}$ and demonstrate for the first time that EIF3D may promote the progression of this malignancy. Similarly with our findings, EIF3D was found to be up-regulated in recent studies in other cancer types including prostate cancer [89], non-small cell lung cancer [90], colon cancer [91], breast cancer [92], renal cell carcinomas [93], melanomas [94] and gliomas [95]. In the aforementioned studies, it was reported that the depletion of EIF3D resulted in cell cycle arrest and reduced the proliferation rate and colony forming ability of the cancer cells. Furthermore, a decreased migratory capacity of the cancer cells upon suppression of EIF3D was also described [89, 92]. All the previously reported data concerning the EIF3D in other cancer types are consistent with our findings. The increasing number of studies indicates that increased level of EIF3D in cancer may be a common feature in several malignancies. In BC, other eIF3 subunits have been investigated and the results are in accordance with our data [96, 97]. Theodorescu's group identified eukaryotic initiation factor 3 subunit B (EIF3B) expression elevated in human bladder and prostate cancers [97]. The depletion of this factor in vitro resulted in decreased proliferation rate due to cell cycle arrest at the G1/S transition, inhibited cell migration, and in vivo delayed tumor growth [97]. In another study, Spilka et al. observed that the upregulation of eukaryotic initiation factor 3 subunit A (EIF3A) in BC was correlated with tumor grade, prompting the authors to suggest that EIF3A 
could serve as a prognostic biomarker in low grade tumors [96]. Knocking down EIF3A decreased proliferation rate, and reduced invasion and tumor formation in mice [96]. The above data and our findings suggest that BC progression may be supported by increased expression and activity of the eIF3 complex. Thus, EIF3D could be potentially amenable to pharmacological targeting.

So far, therapeutic strategies targeting the translational machinery components in cancer focused on the eukaryotic translation initiation factor 4F complex and specifically the EIF4E subunit (reviewed in [50]). Recent evidence, however, supports the existence of an alternative cap-dependent translation mechanism, independent from EIF4E [98]. This recently described model, suggests that translation is driven by EIF3D, through recognition of the $5^{\prime}$ mRNA cap in a subset of mRNAs (such as the cell proliferation regulator c-Jun) that are eIF3-specialized and where EIF4E recruitment is blocked [98]. This gives rise to another layer of cap-dependent translation. Collectively, our results suggest that the development of inhibitors for the subunits of the eIF3 complex (EIF3B, EIF3D) may be a promising research avenue toward pharmaceutical intervention in $\mathrm{BC}$ especially in cases where EIF4E is apparently missing.

The predicted activation of the translational machinery based on the observed proteomics changes in MIBC also included a predicted activation of the mTOR pathway. As illustrated in Supplementary Figure 1, the in silico analysis of the proteomics findings, predicted a hyperactivation state for both the mammalian target of rapamycin complex 1 (mTORC1) and mammalian target of rapamycin complex 2 (mTORC2) with their negative regulator 5' AMP-activated protein kinase (AMPK) detected from the proteomic analysis being down-regulated. RHEB is a member of the small Ras GTPase family [99] that serves as an upstream activator of mTORC1 [100]. The predicted overexpression of RHEB in MIBC compared to NMIBC based on the in silico analysis was confirmed by Western blot. However, interestingly, inactivation of RHEB failed to impact tumor growth in vivo. Existence of mechanisms bypassing mTOR inhibition have been suggested to explain negative results from respective clinical trials (reviewed in [101]). Based on our results, the overexpression of downstream proteins in protein synthesisrelated pathways, such as EIF3D, may be contributing to the acquired resistance of cancer cells to mTOR inhibition, a hypothesis meriting further investigation.

Collectively, our study represents a comprehensive analysis of $\mathrm{BC}$ proteome from patients with muscle invasive and non- muscle invasive disease providing a proteomic component to support molecular integrative studies in the future. Functional analysis suggested a potential therapeutic effect for EIF3D. This finding requires further investigation in animal models, as well as in tumor specimens in relation to muscle invasive molecular subtypes. Determining EIF3D therapeutic potential, especially in tumors where eIF4 inhibitors apparently fail, may open up exciting avenues for further research toward personalized treatment.

\section{MATERIALS AND METHODS}

\section{Patients and tumor characteristics}

$\mathrm{BC}$ tissue specimens were collected from patients undergoing cystectomy or transurethral resection of $\mathrm{BC}$ in medical centers in Greece (Laikon Hospital, Athens) and Germany (Department of Urology and Urological Oncology, Hannover Medical School). Sample collection was approved by the respective local ethics committees (for Athens E.S 618-2012 and for Hannover 614-2009), and all individuals gave written informed consent. Samples from tumor tissue from 11 patients were employed for the proteomic analysis including non-muscle invasive (stage pTa, $n=5$ ) and muscle invasive bladder cancer cases (stage pT2+, $n=6$ ); whereas for the IHC, from a total of 8 patients with pTa, 8 with pT1 and 8 patients with pT2+. Normal controls $(n=6)$; corresponded to normal adjacent epithelium from patients that underwent cystectomy. Tumor stage was determined according to TNM classification of malignant tumors [102], whereas grading was performed in accordance to World Health Organization (WHO) Grading System 2004 [103].

\section{Sample preparation}

Approximately $20 \mathrm{mg}$ of $\mathrm{BC}$ tissue was homogenized in $150 \mu \mathrm{l}$ of lysis buffer (4\% SDS, $0.1 \mathrm{M}$ DTE, $0.1 \mathrm{M}$ Tris- $\mathrm{HCl} \mathrm{pH}$ 7.6) using a blade homogenizer (three cycles of 30-40 s) followed by sonication (15 s per sample). Undissolved materials were removed by centrifugation at $16,000 \mathrm{rcf}$ for $10 \mathrm{~min}$. Protein concentration was determined by the Bradford assay (BioRad, California, USA). Protein extracts $(200 \mu \mathrm{g})$ were processed using filter aided sample preparation (FASP) as described previously [104], with some minor modifications [105]. Briefly, buffer exchange was performed in Amicon Ultra Centrifugal filter devices (0.5 ml, $30 \mathrm{kDa}$ MWCO; Merck, NJ, USA) at 16,000 ref for $15 \mathrm{~min}$ at room temperature. The protein extract was mixed with urea buffer $(8 \mathrm{M}$ urea in $0.1 \mathrm{M}$ Tris- $\mathrm{HCl}$ $\mathrm{pH}$ 8.5) and centrifuged. The concentrate was diluted with urea buffer and centrifugation was repeated. Alkylation of proteins was performed by adding $0.05 \mathrm{M}$ iodoacetamide in urea buffer followed by $20 \mathrm{~min}$ incubation in the dark and centrifugation at $16,000 \mathrm{rcf}$ for $10 \mathrm{~min}$. Additional series of washes were conducted with urea buffer (2 times) and ammonium bicarbonate buffer $\left(50 \mathrm{mM} \mathrm{NH}_{4} \mathrm{HCO}_{3} \mathrm{pH}\right.$ 8,2 times). Tryptic digestion was performed overnight using trypsin to protein ratio 1:100. Peptides were eluted by centrifugation at $16000 \mathrm{rcf}$ for $10 \mathrm{~min}$, lyophilized and stored at $-80^{\circ} \mathrm{C}$ until further use. 


\section{LC-MS/MS analysis}

Tryptic digests were loaded onto a Dionex Ultimate 3000 RSLS nano flow system (Dionex, Camberly, UK). After loading onto a Dionex $0.1 \times 20 \mathrm{~mm} 5 \mu \mathrm{m} \mathrm{C} 18$ nano trap column at a flow rate of $5 \mu \mathrm{l} / \mathrm{min}$ in $0.1 \%$ formic acid and $2 \%$ acetonitrile, samples were applied onto an Acclaim PepMap C18 nano column $75 \mu \mathrm{m} \times 50 \mathrm{~cm}, 2 \mu \mathrm{m}$ $100 \AA$ at a flow rate of $0.3 \mu \mathrm{l} / \mathrm{min}$. The trap and nano flow column were maintained at $35^{\circ} \mathrm{C}$. The samples were eluted with a gradient of solvent $\mathrm{A}: 0.1 \%$ formic acid versus solvent B: $80 \%$ acetonitrile starting at $1 \%$ B for $5 \mathrm{~min}$ rising to $5 \% \mathrm{~B}$ at $10 \mathrm{~min}$ then to $25 \% \mathrm{~B}$ at $360 \mathrm{~min}$ and $65 \% \mathrm{~B}$ at $480 \mathrm{~min}$.

The eluent was ionized using a Proxeon nano spray ESI source operating in positive ion mode into an Orbitrap Velos FTMS (Thermo Finnigan, Bremen, Germany). Ionization voltage was $2.6 \mathrm{kV}$ and the capillary temperature was $200^{\circ} \mathrm{C}$. The mass spectrometer was operated in MS/MS mode scanning from 380 to 2,000 m/z. The top 20 multiply charged ions were selected from each scan for MS/MS analysis using CID at $40 \%$ collision energy. The resolution in MS1 was 60,000 and 7,500 at $\mathrm{m} / \mathrm{z} 400$ for CID in MS2.

\section{Data processing and quantification}

The raw data from LC-MS/MS analysis were evaluated using commercially available Proteome Discoverer (PD) v. 1.2 (Thermo Scientific) and open source Trans-Proteomic Pipeline (TPP) v. 4.6.3 (Institute for Systems Biology, Seattle Proteomic Center; http://tools. proteomecenter.org/wiki/index.php?title=Software:TPP).

Database search was carried out against Human SwissProt Database [106, 107] $(30 / 10 / 2013)$ containing only the canonical sequences with 20,277 reviewed entries using Sequest [108] and X!Tandem [109] search engines in PD and TPP [110, 111], respectively. Both analyses, using PD and TPP, were performed using comparable parameters including a) precursor mass tolerance 10 ppm, b) fragment mass tolerance: $0.8 \mathrm{Da}, \mathrm{c}$ ) fixed modification: carbamidomethylation of cysteine, d) variable modifications: oxidation of methionine and proline, e) not allowing for semitryptic peptides, and f) allowing one missed cleavage. Moreover, using TPP, another database search was also performed against a concatenated database with a shuffled version of decoy database as created using COMPASS [112]. Additionally, to generate appropriate input files, raw data were converted to mzML format using Msconvert (ProteoWizard). Results from TPP were further validated using PeptideProphet [113] and ProteinProphet [114] which are incorporated in the TPP software. Proteins with false positive rate less than $5 \%$ were included for subsequent quantification. For the analysis in PD, dataset was filtered requiring mass deviation below 5 ppm between experimental and theoretical mass and only peptides characterized by high confidence were included. Peptide confidence was assessed based on Xcorr score and charge. Peptides having the charge of $1,2,3,>4$ and the respective XCorr value higher than 1.5, 2, 2.5, 3 were defined as high confidence. In both cases, protein grouping was disabled and proteins identified by a single peptide (unique or shared with other proteins) were also considered.

Quantification analysis was performed using peak area-based quantification (for PD) and spectral counting (for TPP). Given these stringent conditions of data analysis, employing two independent approaches for quantification, all peptides (unique or shared with other proteins) assigned to a protein were taken into consideration in order to maximize proteome coverage. Of note, the inclusion of non-unique peptides seems to not have a significant impact on quantification results (as revealed by correlation analysis performed upon inclusion/exclusion of shared peptides, data not shown). The peak area-based quantification uses precursor ions to assess the relative abundance of identified proteins in the label-free data. For each precursor ion, peak area (i.e. area under the curve) is calculated from the extracted ion chromatogram during data processing in PD by using the Precursor Ions Area Detector node. Protein quantification was based on the protein area values calculated as an average of the area for three most abundant peptides. When the peptide was not identified in the particular sample, the missing values were replaced with zero. Part per million (ppm)-normalization was conducted for the proteins identified in individual samples according to the following formula: Normalized peak area $=($ Peptide peak area/Total peak area) $\times 10^{6}$. The spectral countbased quantification was performed using the Absolute Protein Expression Quantification algorithm (APEX), as described previously [115]. The normalized APEX score was obtained by dividing individual protein values by the total APEX score for each sample. The mean protein abundance per groups (pTa or $\mathrm{pT} 2+$ ) and SD were then calculated. The changes in the relative abundance were represented by the fold change, calculated as a ratio for muscle invasive $(\mathrm{pT} 2+)$ to non-muscle invasive cases (pTa). In both approaches, only proteins consistently reported in $\geq 60 \%$ of the samples (at least in one group: pTa and/or pT2+) were considered as credible and included for further statistical assessment.

\section{Statistical analysis}

Statistical analysis was performed using the SPSS Statistical Software (SPSS 17.0, IBM). The distribution of the data was evaluated using the Kolmogorov-Smirnov test. Since a normal distribution was observed, independent sample $t$-test was applied. Proteins with a $p$-value below 0.05 were considered as statistically significant. 


\section{Bioinformatics analysis}

The impact of the differentially expressed proteins was further evaluated in the context of pathway as well as interactome network analyses. The pathways were generated using QIAGEN's Ingenuity Pathway Analysis (IPA ${ }^{\circledR}$, QIAGEN Redwood City, www.qiagen.com/ ingenuity). Statistical analysis was conducted by using right-tailed Fisher's exact test and pathways with a $p$-value below 0.05 were considered as significant. The protein interaction network was created using STRING v. 9.1 (Search Tool for the Retrieval of Interacting Genes/ Proteins, http://string-db.org/) using default settings [116].

\section{Immunohistochemistry on tissue microarrays}

Verification of proteomics findings was performed using immunohistochemistry (IHC) staining on tissue microarrays, as described previously [105]. Briefly, immunochistochemical analysis was performed for (i) BRO1 domain-containing protein BROX (BROX; rabbit polyclonal anti-BROX, Novus Biologicals, dilution 1:300), (ii) Membrane-associated progesterone receptor component 1 (PGRMC1; rabbit polyclonal anti-PGRMC1, Proteintech, dilution 1:50), (iii) Tissue alpha-L-fucosidase (FUCA1; rabbit polyclonal anti-FUCA1, Proteintech, dilution $1: 100$ ) and (iv) $26 \mathrm{~S}$ proteasome non-ATPase regulatory subunit 12 (PSMD12; rabbit polyclonal anti-PSMD12, Novus Biologicals, dilution 1:400). Staining intensity was quantified using ImageJ software as described [105].

\section{Cell lines and conditioned media}

The human embryonic kidney cell line 293T and the human fibrosarcoma cell line HT1080 were obtained from American Type Culture Collection (ATCC). The human bladder cancer cell line T24M, represents the metastatic variant of T24 cells and was developed by our group after following cycles of subcutaneous injections of T24 cells in mice and re-isolation and culture of metastatic cells in vitro as previously described [117]. All the cell lines were cultured in DMEM media (Gibco-BRL, Paisley, Scotland UK) supplemented with $10 \%$ fetal bovine serum (FBS; Gibco-BRL, Paisley, Scotland UK) and 1\% PenicillinStreptomycin (Pen-Strep; Gibco-Invitrogen) at $37^{\circ} \mathrm{C}$ in $5 \%$ $\mathrm{CO}_{2}$ under sterile conditions. For the preparation of the conditioned media (CM), T24M cells were incubated in DMEM supplemented with $2 \%$ FBS, $1 \%$ Pen-strep for $48 \mathrm{~h}$ at $37^{\circ} \mathrm{C}$ in $5 \% \mathrm{CO}_{2}$. Subsequently, the $\mathrm{CM}$ was collected after centrifugation at $2000 \mathrm{rcf}$ for $10 \mathrm{~min}$ in order to remove dead cells and debris, as described before [118].

\section{Production of shRNA lentiviruses and transduction of the target cell lines}

The knockdown study was performed using lentiviral-mediated RNA interference. The lentiviral vectors with the sequences for the shRNAs were purchased from the Erasmus Center for Biomics. The shRNA sequences targeting EIF3D and RHEB were 5'-CCGGCCTCAGACATA CTCCATAGATCTCGAGATCTATGGAGTATGTCTGA GGTTTTTG-3', respectively. A scrambled shRNA (shscramble) was used as control, as previously described [119]. For the lentivirus production, a four plasmid system was used for the transient transfection of 293T cells as previously described [120,121], followed by concentration with Amicon Ultra Centrifugal Filters-100K Units (Merck Millipore). The titers of the concentrated lentiviruses were determined after infection of HT1080 cells with serial dilutions of the viral stock. The titers were estimated at $5 \times 10^{8}-10^{9}$ infection units (IU) $/ \mathrm{ml}$. The lentiviruses were then used for the transduction of the target cell line T24M. As control T24M cells transduced with a lentivirus for shscramble was used. The knockdown effect was evaluated at the RNA level by real-time PCR and at the protein level by Western blot analyses as described in the following sections.

\section{Real-time PCR}

Total RNA was isolated from T24Mshscramble, T24MshEIF3D and T24MshRHEB cells 4 days after the transduction and from untransduced T24M cells using the TRI Reagent (Sigma-Aldrich) according to the manufacturer's instructions. Total RNA was also isolated from T24M, T24Mshscramble, T24MshEIF3D and T24MshRHEB tumors from the respective groups of mice by using the same protocol. For the cDNA synthesis $1 \mu \mathrm{g}$ of total RNA was used as starting material for SuperScript II reverse transcriptase (Invitrogen). Real-time PCR was performed on a SaCycler-96 (Sacace Biotechnologies) using the SYBR Green master mix (Kapa Biosystems) and the following primers: EIF3D (forward): $5^{\prime}-\mathrm{CAGCG}$ GAATCGAATGAGATTTGC-3' EIF3D (reverse): 5'-GTT TGGCACTCTTAGGCAGGA-3', RHEB (forward): 5'-TT GTGGACTCCTACGATCCAA-3', RHEB (reverse): 5'-GGCTGTGTCTACAAGTTGAAGAT-3' according to the manufacturer's protocol. GAPDH was used as an internal control. The relative gene expression analysis was performed by implementing the $2^{-\Delta \Delta C t}$ method.

\section{Western blot analysis}

Total cell extracts were obtained from T24Mshscramble, T24MshEIF3D and T24MshRHEB cells 4 days after the lentiviral transduction and from untransduced T24M cells. Total cell extracts were also obtained from T24M, T24M shscramble, T24M shEIF3D and T24M shRHEB tumors from the respective groups of mice. Protein extracts were separated by $10 \%$ SDS-PAGE under reducing conditions and transferred to HybondECL nitrocellulose membrane (Amersham Biosciences). The membranes were blocked in TBS- $0.1 \%$ Tween $5 \%$ 
milk for 2 hours at room temperature, then they were washed with TBS- $0.1 \%$ Tween and incubated overnight at $4{ }^{\circ} \mathrm{C}$ with the following primary antibodies: rabbit antihuman EIF3D (Proteintech, dilution 1:400), mouse antihuman RHEB (Santa Cruz, dilution 1:500). Membranes were washed again as described above and then incubated for $2 \mathrm{~h}$ at room temperature with secondary antibodies conjugated with HRP (anti-rabbit, Amersham, dilution 1:10,000; anti-mouse, Santa Cruz, dilution 1:2,000). After washing membranes with TBS- $0.1 \%$ Tween, the target proteins were detected with an ECL detection kit (Thermo Scientific). B-actin was used as a loading control. The films were scanned at a GS-800 imaging densitometer (BioRad) in transmission mode and densitometry analysis of the results was performed using the Quantity One software (BioRad).

\section{MTS cell proliferation assay}

T24M, T24Mshscramble, T24MshEIF3D and T24MshRHEB cells were seeded in 96-well plates at a density of 1,000 cells per well and cultured for 3 and 4 days, respectively. At the indicated time points the recommended amount of MTS reagent (Promega, Madison, USA) was added into each well of the 96-well plate and the cells were then incubated for additional 3 hours at $37^{\circ} \mathrm{C}$ in a humidified, $5 \% \mathrm{CO}_{2}$ atmosphere. The absorbance was then recorded at $490 \mathrm{~nm}$ with a 96-well plate reader (SPECTROstar Nano, BMG LABTECH). For the calculation of the percentage difference in the proliferation rate the following formula was used: $\left[\left(\mathrm{OD}_{\text {day }} \times-\mathrm{OD}_{\text {day } 0}\right) /\left(\mathrm{ODcontrol}_{\text {day }} \times-\right.\right.$ ODcontrol $\left.\left._{\text {day } 0}\right)\right]$ $\times 100$. Each experiment was performed in five replicates and repeated two times.

\section{Colony formation assay}

T24M, T24Mshscramble, T24MshEIF3D and T24MshRHEB cells were plated at a density of 1000 cells per well in 96-well plates pre-coated with matrigel (BD Biosciences, New Jersey, USA) according to the manufacturer's instructions. The cells were incubated for 10 days at $37^{\circ} \mathrm{C}$ in a humidified, $5 \% \mathrm{CO}_{2}$ atmosphere. Photographs were taken from 5 fields of view $(\times 10$ or $\times 5)$ for each well, using a Leica CTR MIC microscope. The number and the size of the colonies were counted by using the Image J 1.49v software. Two independent experiments were performed, each including three replicates.

\section{Transwell migration assay}

Transwell migration assays were performed as previously described $[118,120,122]$. In brief, $5 \times 10^{4}$ cells T24M, T24Mshscramble, T24MshEIF3D and T24MshRHEB were added to the inside compartment of transwell inserts with $5 \mu \mathrm{m}$ pores (Corning-Costar,
Cambridge, MA). As stimulus, CM derived from T24M cells was added at the bottom chamber of the transwell plate. Cells were allowed to migrate for 6 hours. Subsequently, the top of each insert was washed with PBS and the cells that had not migrated through the membrane were removed with a wet cotton swab. The migrated cells at the bottom of the insert were fixed with $4 \%$ paraformaldehyde (Sigma Aldrich) and stained with eosinhaematoxylin. The migratory capacity of the cells was assessed by counting the number of the cells that passed through the pore membrane. Photographs from 5 different fields (10x) of each insert were taken using a Leica CTR MIC microscope. Stained cells were counted using the Image J 1.49v software. Two independent experiments were performed, each including two replicates. Statistical analysis was performed using Student's $t$-test.

\section{Animal experiments}

The NOD-SCID mice used for the in vivo experiments were housed and maintained at the Animal Facility of the Biomedical Research Foundation of the Academy of Athens. The procedures applied for the animal care and treatment were according to the recommendations of the Federation of European Laboratory Animal Science Associations (FELASA) and also approved by the Institutional Animal Care and Use Committee. For the development of the tumors, $3.3 \times 10^{6} \mathrm{~T} 24 \mathrm{M}$ shEIF3D $(n=14)$, T24M shRHEB $(n=13)$, T24M shscramble $(n=12)$ and T24M $(n=12)$ cells were administered subcutaneously into the tail base of 8-10 weeks old male NOD/SCID mice, as described previously [119, 120]. The tumor size was measured on a weekly basis by using a caliper until the tumors reached an average diameter of $12-15 \mathrm{~mm}$. At that time point the animals were sacrificed and tumors, lungs, livers, spleens and kidneys were collected. In the presence of tumor ulceration or bleeding the mice were sacrificed earlier.

\section{Abbreviations}

ACTN: alpha actinins; ACTN4: actinin alpha 4; ADIRF: adipogenesis regulatory factor; AGR2: anterior gradient protein 2 homolog; AMPK: 5' AMP-activated protein kinase; ANXA: annexins; ANXA10: annexin A10; APEX: Absolute Protein Expression Quantification algorithm; ATCC: American Type Culture Collection; BC: bladder cancer; BPGM: bisphosphoglycerate mutase; BROX: BRO1 domain-containing protein BROX; CCND1: cyclin D1; CDH13: cadherin 13; CDKN1B: cyclin dependent kinase inhibitor 1B; CDKN2A: cyclin dependent kinase inhibitor 2A; CIS: carcinoma in situ; CM: conditioned media; COPA: coatomer protein complex subunit alpha; CTLA-4: cytotoxic T-lymphocyte associated protein 4; CTSE: cathepsin E; ECM: extracellular matrix; eIF2: eukaryotic initiation factor 2; eIF3: eukaryotic 
initiation factor 3; EIF3A: eukaryotic translation initiation factor 3 subunit A; EIF3B: eukaryotic translation initiation factor 3 subunit B; EIF3D: eukaryotic translation initiation factor 3 subunit D; eIF4: eukaryotic initiation factor 4; ESCTR: endosomal sorting complex required for transport; FASP: filter aided sample preparation; FBLN2: fibulin 2; FBS: fetal bovine serum; FELASA: Federation of European Laboratory Animal Science Associations; FGFR: fibroblast growth factor receptors; FUCA1: tissue alpha-L-fucosidase; G6PD: glucose-6-phosphate 1-dehydrogenase; GPNMB: transmembrane glycoprotein NMB; HPGD: hydroxyprostaglandin dehydrogenase 15(NAD); HRAS: HRas proto-oncogene, GTPase; IHC: immunohistochemistry; IU: infection units; KRT19: keratin type I cytoskeletal 19; LC-MS/MS: liquid chromatographytandem mass spectrometry; MIBC: muscle invasive bladder cancers; mTOR: mammalian target of rapamycin; mTORC1: mammalian target of rapamycin complex 1; mTORC2: mammalian target of rapamycin complex 2; NMIBC: non-muscle invasive bladder cancers; NRF2: nuclear factor, erythroid 2 like 2; p70S6K: ribosomal protein S6 kinase beta-1; PALLD: palladin; PD: Proteome Discoverer; PD-1: programmed cell death protein 1; PenStrep: Penicillin-Streptomycin; PGAM1: phosphoglycerate mutase 1; PGRMC1: membrane-associated progesterone receptor component 1; PI3K-AKT-mTOR: phosphatidylinositol 3-kinase (PI3K)- protein kinase B (Akt)-mTOR; PRKAG2: 5'-AMP-activated protein kinase subunit gamma-2; PSMD12: 26S proteasome non-ATPase regulatory subunit 12 ; RB1: RB transcriptional corepressor 1; RHEB: Ras homolog enriched in brain; RTCA: RNA 3'-terminal phosphate cyclase; SEC22B: vesicle-trafficking protein SEC22b; SND1: staphylococcal nuclease domaincontaining protein 1; STMN1: stathmin 1; TAGLN2: transgelin 2; TARS: threonyl-TRNA synthetase; TGFBI: transforming growth factor-beta-induced protein ig-h3; TGOLN2: trans-golgi network integral membrane protein 2; TNM: TNM Classification of Malignant Tumours; TP53: tumor protein P53; TPP: Trans-Proteomic Pipeline; TYMP: thymidine phosphorylase; UBB: polyubiquitin-B; UBE2D3: ubiquitin-conjugating enzyme E2 D3; UCHL3: ubiquitin carboxyl-terminal hydrolase isozyme L3; UGP2: UTP-glucose-1-phosphate uridylyltransferase; VEGF: vascular endothelial growth factor; WHO: World Health Organization.

\section{Authors' contributions}

A.V, H.M, M.G.R, A.L and M.M* conceived and designed the experiments. A.V, H.M and M.G.R supervised the study. A.L, M.M*, M.M, W.M, V.L performed experiments. A.L conducted the proteomics experiments and analyzed the data and M.M* performed and analyzed the functional experiments. A.L, M.M, M.F, M.D contributed to bioinformatics analysis and interpretation of the data. A.L, M.M*, M.M, M.F, J.Z, W.K, M.G.R, A.V,
H.M contributed to the drafting and revising of manuscript. I.K, K.S, M.C.H, A.S.M contributed to the collection of the clinical samples. All authors read the manuscript and approved the final version.

\section{ACKNOWLEDGMENTS}

\author{
Not applicable
}

\section{CONFLICTS OF INTEREST}

Harald Mischak is the founder and co-owner of Mosaiques Diagnostics. Dr. Maria Frantzi is employed by Mosaiques Diagnostics. Dr. Agnieszka Latosinska is also currently employed by Mosaiques Diagnostics.

\section{FUNDING}

The work was supported by the BCMolMed grant (PITN-GA-2012-317450) from the FP7-PEOPLE-2012ITN program.

\section{REFERENCES}

1. Torre LA, Bray F, Siegel RL, Ferlay J, Lortet-Tieulent J, Jemal A. Global cancer statistics, 2012. CA Cancer J Clin. 2015; 65:87-108.

2. Arnold M, Karim-Kos HE, Coebergh JW, Byrnes G, Antilla A, Ferlay J, Renehan AG, Forman D, Soerjomataram I. Recent trends in incidence of five common cancers in 26 European countries since 1988: Analysis of the European Cancer Observatory. Eur J Cancer. 2015; 51:1164-1187.

3. Babjuk M, Bohle A, Burger M, Capoun O, Cohen D, Comperat EM, Hernandez V, Kaasinen E, Palou J, Roupret M, van Rhijn BW, Shariat SF, Soukup V, et al. EAU Guidelines on Non-Muscle-invasive Urothelial Carcinoma of the Bladder: Update 2016. Eur Urol. 2017; 71:447-461.

4. Kaufman DS, Shipley WU, Feldman AS. Bladder cancer. Lancet. 2009; 374:239-249.

5. Witjes JA, Comperat E, Cowan NC, De Santis M, Gakis G, Lebret T, Ribal MJ, Van der Heijden AG, Sherif A, European Association of U. EAU guidelines on muscleinvasive and metastatic bladder cancer: summary of the 2013 guidelines. Eur Urol. 2014; 65:778-792.

6. Prasad SM, Decastro GJ, Steinberg GD, Medscape. Urothelial carcinoma of the bladder: definition, treatment and future efforts. Nat Rev Urol. 2011; 8:631-642.

7. Siegel R, DeSantis C, Virgo K, Stein K, Mariotto A, Smith T, Cooper D, Gansler T, Lerro C, Fedewa S, Lin C, Leach C, Cannady RS, et al. Cancer treatment and survivorship statistics, 2012. CA Cancer J Clin. 2012; 62:220-241.

8. Davarpanah NN, Yuno A, Trepel JB, Apolo AB. Immunotherapy: a new treatment paradigm in bladder cancer. Curr Opin Oncol. 2017.

9. Necchi A, Lo Vullo S, Mariani L, Raggi D, Giannatempo P, Calareso G, Togliardi E, Crippa F, Di Genova N, Perrone F, 
Colecchia M, Paolini B, Pelosi G, et al. An open-label, single-arm, phase 2 study of the Aurora kinase A inhibitor alisertib in patients with advanced urothelial cancer. Invest New Drugs. 2016; 34:236-242.

10. di Martino E, Tomlinson DC, Williams SV, Knowles MA. A place for precision medicine in bladder cancer: targeting the FGFRs. Future Oncol. 2016; 12:2243-2263.

11. Cancer Genome Atlas Research N. Comprehensive molecular characterization of urothelial bladder carcinoma. Nature. 2014; 507:315-322.

12. Czerniak B, Dinney C, McConkey D. Origins of Bladder Cancer. Annu Rev Pathol. 2016.

13. Knowles MA, Hurst CD. Molecular biology of bladder cancer: new insights into pathogenesis and clinical diversity. Nat Rev Cancer. 2015; 15:25-41.

14. Netto GJ. Molecular biomarkers in urothelial carcinoma of the bladder: are we there yet? Nat Rev Urol. 2012; 9:41-51.

15. Gui Y, Guo G, Huang Y, Hu X, Tang A, Gao S, Wu R, Chen C, Li X, Zhou L, He M, Li Z, Sun X, et al. Frequent mutations of chromatin remodeling genes in transitional cell carcinoma of the bladder. Nat Genet. 2011; 43:875-878.

16. Iyer G, Al-Ahmadie H, Schultz $N$, Hanrahan AJ, Ostrovnaya I, Balar AV, Kim PH, Lin O, Weinhold N, Sander C, Zabor EC, Janakiraman M, Garcia-Grossman IR, et al. Prevalence and co-occurrence of actionable genomic alterations in high-grade bladder cancer. J Clin Oncol. 2013; 31:3133-3140.

17. Sjodahl G, Lauss M, Lovgren K, Chebil G, Gudjonsson S, Veerla S, Patschan O, Aine M, Ferno M, Ringner M, Mansson W, Liedberg F, Lindgren D, et al. A molecular taxonomy for urothelial carcinoma. Clin Cancer Res. 2012; 18:3377-3386.

18. Choi W, Porten S, Kim S, Willis D, Plimack ER, HoffmanCensits J, Roth B, Cheng T, Tran M, Lee IL, Melquist J, Bondaruk J, Majewski T, et al. Identification of distinct basal and luminal subtypes of muscle-invasive bladder cancer with different sensitivities to frontline chemotherapy. Cancer Cell. 2014; 25:152-165.

19. Lerner SP, McConkey DJ, Hoadley KA, Chan KS, Kim WY, Radvanyi F, Hoglund M, Real FX. Bladder Cancer Molecular Taxonomy: Summary from a Consensus Meeting. Bladder Cancer. 2016; 2:37-47.

20. Biton A, Bernard-Pierrot I, Lou Y, Krucker C, Chapeaublanc E, Rubio-Perez C, Lopez-Bigas N, Kamoun A, Neuzillet Y, Gestraud P, Grieco L, Rebouissou S, de Reynies A, et al. Independent component analysis uncovers the landscape of the bladder tumor transcriptome and reveals insights into luminal and basal subtypes. Cell Rep. 2014; 9:1235-1245.

21. Aine M, Eriksson P, Liedberg F, Hoglund M, Sjodahl G. On Molecular Classification of Bladder Cancer: Out of One, Many. Eur Urol. 2015; 68:921-923.

22. Kurtoglu M, Davarpanah NN, Qin R, Powles T, Rosenberg JE, Apolo AB. Elevating the Horizon: Emerging
Molecular and Genomic Targets in the Treatment of Advanced Urothelial Carcinoma. Clin Genitourin Cancer. 2015; 13:410-420.

23. Guo T, Kouvonen P, Koh CC, Gillet LC, Wolski WE, Rost HL, Rosenberger G, Collins BC, Blum LC, Gillessen S, Joerger M, Jochum W, Aebersold R. Rapid mass spectrometric conversion of tissue biopsy samples into permanent quantitative digital proteome maps. Nat Med. 2015; 21:407-413.

24. Peng XC, Gong FM, Chen Y, Qiu M, Cheng K, Tang J, Ge J, Chen N, Zeng H, Liu JY. Proteomics identification of PGAM1 as a potential therapeutic target for urothelial bladder cancer. J Proteomics. 2016; 132:85-92.

25. Chen CL, Chung $\mathrm{T}, \mathrm{Wu} \mathrm{CC}, \mathrm{Ng} \mathrm{KF}, \mathrm{Yu}$ JS, Tsai CH, Chang YS, Liang Y, Tsui KH, Chen YT. Comparative Tissue Proteomics of Microdissected Specimens Reveals Novel Candidate Biomarkers of Bladder Cancer. Mol Cell Proteomics. 2015; 14:2466-2478.

26. Oezdemir RF, Gaisa NT, Lindemann-Docter K, Gostek S, Weiskirchen R, Ahrens M, Schwamborn K, Stephan C, Pfister D, Heidenreich A, Knuechel R, Henkel C. Proteomic tissue profiling for the improvement of grading of noninvasive papillary urothelial neoplasia. Clin Biochem. 2012; 45:7-11.

27. Niu HT, Yang CM, Chen B, Dong Q. Biomarker research and some deduction in superficial bladder cancer cells combined with corresponding stroma. Cancer Biomark. 2011; 10:109-116.

28. Rotterud R, Malmstrom PU, Wahlqvist R, Tasken KA. The star chart to Ta bladder cancer: an unsophisticated analysis of two-dimensional gel electrophoresis proteome maps. Scand J Urol Nephrol. 2010; 44:76-83.

29. Li J, Abraham S, Cheng L, Witzmann FA, Koch M, Xie J, Rahman M, Mohammed SI. Proteomic-based approach for biomarkers discovery in early detection of invasive urothelial carcinoma. Proteomics Clin Appl. 2008; 2:78-89.

30. Liu PF, Cao YW, Jiang HP, Wang YH, Yang XC, Wang XS, Niu HT. Heterogeneity research in muscle-invasive bladder cancer based on differential protein expression analysis. Med Oncol. 2014; 31: 21.

31. Niu HT, Zhang YB, Jiang HP, Cheng B, Sun G, Wang Y, E YJ, Pang de Q, Chang JW. Differences in shotgun protein expression profile between superficial bladder transitional cell carcinoma and normal urothelium. Urol Oncol. 2009; 27:400-406.

32. Niu H, Jiang H, Cheng B, Li X, Dong Q, Shao L, Liu S, Wang X. Stromal proteome expression profile and muscle-invasive bladder cancer research. Cancer Cell Int. 2012; 12:39.

33. Niu HT, Qi XJ, Liu YQ, Cao YW, Dong Q, Wang XS. Parallel proteomic analysis in muscle-invasive bladder transitional cell carcinoma and cancer-related stroma. Genet Mol Res. 2013; 12:4251-4263.

34. Liu PF, Wang YH, Cao YW, Jiang HP, Yang XC, Wang XS, Niu HT. Far from resolved: stromal cell-based iTRAQ 
research of muscle-invasive bladder cancer regarding heterogeneity. Oncol Rep. 2014; 32:1489-1496.

35. Brakhuis BJ, Leemans CR, Brakenhoff RH. Using tissue adjacent to carcinoma as a normal control: an obvious but questionable practice. J Pathol. 2004; 203:620-621.

36. Tseng-Rogenski S, Gee J, Ignatoski KW, Kunju LP, Bucheit A, Kintner HJ, Morris D, Tallman C, Evron J, Wood CG, Grossman HB, Lee CT, Liebert M. Loss of 15-hydroxyprostaglandin dehydrogenase expression contributes to bladder cancer progression. Am J Pathol. 2010; 176:1462-1468.

37. Arima J, Imazono Y, Takebayashi Y, Nishiyama K, Shirahama T, Akiba S, Furukawa T, Akiyama S, Ohi Y. Expression of thymidine phosphorylase as an indicator of poor prognosis for patients with transitional cell carcinoma of the bladder. Cancer. 2000; 88:1131-1138.

38. Li CF, Shen KH, Huang LC, Huang HY, Wang YH, Wu TF. Annexin-I overexpression is associated with tumour progression and independently predicts inferior diseasespecific and metastasis-free survival in urinary bladder urothelial carcinoma. Pathology. 2010; 42:43-49.

39. Sheng KH, Yao YC, Chuang SS, Wu H, Wu TF. Search for the tumor-related proteins of transition cell carcinoma in Taiwan by proteomic analysis. Proteomics. 2006; 6:1058-1065.

40. Munksgaard PP, Mansilla F, Brems Eskildsen AS, Fristrup N, Birkenkamp-Demtroder K, Ulhoi BP, Borre M, Agerbaek M, Hermann GG, Orntoft TF, Dyrskjot L. Low ANXA10 expression is associated with disease aggressiveness in bladder cancer. Br J Cancer. 2011; 105:1379-1387.

41. Wang R, Morris DS, Tomlins SA, Lonigro RJ, Tsodikov A, Mehra R, Giordano TJ, Kunju LP, Lee CT, Weizer AZ, Chinnaiyan AM. Development of a multiplex quantitative PCR signature to predict progression in non-muscleinvasive bladder cancer. Cancer Res. 2009; 69:3810-3818.

42. Koizumi T, Nakatsuji H, Fukawa T, Avirmed S, Fukumori T, Takahashi M, Kanayama H. The role of actinin-4 in bladder cancer invasion. Urology. 2010; 75:357-364.

43. Yoshii H, Ito K, Asano T, Horiguchi A, Hayakawa M, Asano T. Increased expression of alpha-actinin-4 is associated with unfavorable pathological features and invasiveness of bladder cancer. Oncol Rep. 2013; 30:1073-1080.

44. Schiffer E, Vlahou A, Petrolekas A, Stravodimos K, Tauber R, Geschwend JE, Neuhaus J, Stolzenburg JU, Conaway MR, Mischak H, Theodorescu D. Prediction of muscle-invasive bladder cancer using urinary proteomics. Clin Cancer Res. 2009; 15:4935-4943.

45. Bhagirath D, Abrol N, Khan R, Sharma M, Seth A, Sharma A. Expression of CD147, BIGH3 and Stathmin and their potential role as diagnostic marker in patients with urothelial carcinoma of the bladder. Clin Chim Acta. 2012; 413:1641-1646.

46. Lin Y, Sun G, Liu X, Chen Y, Zhang C. Clinical significance of T-cadherin tissue expression in patients with bladder transitional cell carcinoma. Urol Int. 2011; 86:340-345.

47. Fristrup N, Ulhoi BP, Birkenkamp-Demtroder $\mathrm{K}$, Mansilla F, Sanchez-Carbayo M, Segersten U, Malmstrom PU, Hartmann A, Palou J, Alvarez-Mugica M, Zieger K, Borre M, Orntoft TF, et al. Cathepsin E, maspin, $\mathrm{Plk}$, and survivin are promising prognostic protein markers for progression in non-muscle invasive bladder cancer. Am J Pathol. 2012; 180:1824-1834.

48. Inoki K, Kim J, Guan KL. AMPK and mTOR in cellular energy homeostasis and drug targets. Annu Rev Pharmacol Toxicol. 2012; 52:381-400.

49. Pinto-Leite R, Arantes-Rodrigues R, Sousa N, Oliveira PA, Santos L. mTOR inhibitors in urinary bladder cancer. Tumour Biol. 2016; 37:11541-11551.

50. Bhat M, Robichaud N, Hulea L, Sonenberg N, Pelletier J, Topisirovic I. Targeting the translation machinery in cancer. Nat Rev Drug Discov. 2015; 14:261-278.

51. Gust KM, So AI. The role of mTOR in bladder cancer. Cancer Biol Ther. 2009; 8:2348-2350.

52. Ma XM, Blenis J. Molecular mechanisms of mTORmediated translational control. Nat Rev Mol Cell Biol. 2009; 10:307-318.

53. Wang X, Proud CG. The mTOR pathway in the control of protein synthesis. Physiology (Bethesda). 2006; 21:362-369.

54. Inoki K, Ouyang H, Li Y, Guan KL. Signaling by target of rapamycin proteins in cell growth control. Microbiol Mol Biol Rev. 2005; 69:79-100.

55. Frantzi M, Latosinska A, Fluhe L, Hupe MC, Critselis E, Kramer MW, Merseburger AS, Mischak H, Vlahou A. Developing proteomic biomarkers for bladder cancer: towards clinical application. Nat Rev Urol. 2015; 12:317-330.

56. Bhat A, Heinzel A, Mayer B, Perco P, Muhlberger I, Husi H, Merseburger AS, Zoidakis J, Vlahou A, Schanstra JP, Mischak H, Jankowski V. Protein interactome of muscle invasive bladder cancer. PLoS One. 2015; 10: e0116404.

57. Frantzi M, van Kessel KE, Zwarthoff EC, Marquez M, Rava M, Malats N, Merseburger AS, Katafigiotis I, Stravodimos K, Mullen W, Zoidakis J, Makridakis M, Pejchinovski $\mathrm{M}$, et al. Development and Validation of Urine-based Peptide Biomarker Panels for Detecting Bladder Cancer in a Multi-center Study. Clin Cancer Res. 2016; 22:4077-4086.

58. Listinsky JJ, Siegal GP, Listinsky CM. Alpha-L-fucose: a potentially critical molecule in pathologic processes including neoplasia. Am J Clin Pathol. 1998; 110:425-440.

59. Yuan K, Listinsky CM, Singh RK, Listinsky JJ, Siegal GP. Cell surface associated alpha-L-fucose moieties modulate human breast cancer neoplastic progression. Pathol Oncol Res. 2008; 14:145-156.

60. Yuan K, Kucik D, Singh RK, Listinsky CM, Listinsky JJ, Siegal GP. Alterations in human breast cancer adhesionmotility in response to changes in cell surface glycoproteins displaying alpha-L-fucose moieties. Int J Oncol. 2008; 32:797-807. 
61. Listinsky JJ, Siegal GP, Listinsky CM. The emerging importance of alpha-L-fucose in human breast cancer: a review. Am J Transl Res. 2011; 3:292-322.

62. Ichioka F, Kobayashi R, Katoh K, Shibata H, Maki M. Brox, a novel farnesylated Brol domain-containing protein that associates with charged multivesicular body protein 4 (CHMP4). FEBS J. 2008; 275:682-692.

63. Mu R, Dussupt V, Jiang J, Sette P, Rudd V, Chuenchor W, Bello NF, Bouamr F, Xiao TS. Two distinct binding modes define the interaction of Brox with the C-terminal tails of CHMP5 and CHMP4B. Structure. 2012; 20:887-898.

64. Zhai Q, Landesman MB, Robinson H, Sundquist WI, Hill CP. Structure of the Brol domain protein BROX and functional analyses of the ALIX Brol domain in HIV-1 budding. PLoS One. 2011; 6:e27466.

65. Li CW, Chen BS. Network Biomarkers of Bladder Cancer Based on a Genome-Wide Genetic and Epigenetic Network Derived from Next-Generation Sequencing Data. Dis Markers. 2016; 2016:4149608.

66. Livneh I, Cohen-Kaplan V, Cohen-Rosenzweig C, Avni N, Ciechanover A. The life cycle of the $26 \mathrm{~S}$ proteasome: from birth, through regulation and function, and onto its death. Cell Res. 2016; 26:869-885.

67. Frankland-Searby S, Bhaumik SR. The $26 \mathrm{~S}$ proteasome complex: an attractive target for cancer therapy. Biochim Biophys Acta. 2012; 1825:64-76.

68. Grigoreva TA, Tribulovich VG, Garabadzhiu AV, Melino G, Barlev NA. The 26S proteasome is a multifaceted target for anti-cancer therapies. Oncotarget. 2015; 6:24733-24749. doi: 10.18632/oncotarget.4619.

69. Chi BH, Kim SJ, Seo HK, Seo HH, Lee SJ, Kwon JK, Lee TJ, Chang IH. P70S6K and Elf4E Dual Inhibition Is Essential to Control Bladder Tumor Growth and Progression in Orthotopic Mouse Non-muscle Invasive Bladder Tumor Model. J Korean Med Sci. 2015; 30:308-316.

70. Crew JP, Fuggle S, Bicknell R, Cranston DW, de Benedetti A, Harris AL. Eukaryotic initiation factor-4E in superficial and muscle invasive bladder cancer and its correlation with vascular endothelial growth factor expression and tumour progression. Br J Cancer. 2000; 82:161-166.

71. Genua M, Xu SQ, Buraschi S, Peiper SC, Gomella LG, Belfiore A, Iozzo RV, Morrione A. Proline-rich tyrosine kinase 2 (Pyk2) regulates IGF-I-induced cell motility and invasion of urothelial carcinoma cells. PLoS One. 2012; 7:e40148.

72. Iozzo RV, Buraschi S, Genua M, Xu SQ, Solomides CC, Peiper SC, Gomella LG, Owens RC, Morrione A. Decorin antagonizes IGF receptor I (IGF-IR) function by interfering with IGF-IR activity and attenuating downstream signaling. J Biol Chem. 2011; 286:34712-34721.

73. Kyou Kwon J, Kim SJ, Hoon Kim J, Mee Lee K, Ho Chang I. Dual inhibition by S6K1 and Elf4E is essential for controlling cellular growth and invasion in bladder cancer. Urol Oncol. 2014; 32: 51 e27-35.

74. Liu S, Li Y, Lin T, Fan X, Liang Y, Heemann U. High dose human insulin and insulin glargine promote T24 bladder cancer cell proliferation via PI3K-independent activation of Akt. Diabetes Res Clin Pract. 2011; 91:177-182.

75. Metalli D, Lovat F, Tripodi F, Genua M, Xu SQ, Spinelli M, Alberghina L, Vanoni M, Baffa R, Gomella LG, Iozzo RV, Morrione A. The insulin-like growth factor receptor I promotes motility and invasion of bladder cancer cells through Akt- and mitogen-activated protein kinasedependent activation of paxillin. Am J Pathol. 2010; 176:2997-3006.

76. Park SJ, Lee TJ, Chang IH. Role of the mTOR Pathway in the Progression and Recurrence of Bladder Cancer: An Immunohistochemical Tissue Microarray Study. Korean J Urol. 2011; 52:466-473.

77. Saito T, Tomita Y, Kawasaki T, Bilim V, Takahashi K. Subsequent activation of mitogen-activated protein kinase after adhesion of transitional cell cancer cells to fibronectin. Urol Int. 2002; 69:125-128.

78. Wang Y, Luo H, Li Y, Chen T, Wu S, Yang L. hsa-miR-96 up-regulates MAP4K1 and IRS1 and may function as a promising diagnostic marker in human bladder urothelial carcinomas. Mol Med Rep. 2012; 5:260-265.

79. Watanabe T, Shinohara N, Moriya K, Sazawa A, Kobayashi Y, Ogiso Y, Takiguchi M, Yasuda J, Koyanagi T, Kuzumaki N, Hashimoto A. Significance of the Grb2 and son of sevenless (Sos) proteins in human bladder cancer cell lines. IUBMB Life. 2000; 49:317-320.

80. Ruggero D. Translational control in cancer etiology. Cold Spring Harb Perspect Biol. 2013; 5.

81. Silvera D, Formenti SC, Schneider RJ. Translational control in cancer. Nat Rev Cancer. 2010; 10:254-266.

82. Stumpf CR, Ruggero D. The cancerous translation apparatus. Curr Opin Genet Dev. 2011; 21:474-483.

83. Loreni F, Mancino M, Biffo S. Translation factors and ribosomal proteins control tumor onset and progression: how? Oncogene. 2014; 33:2145-2156.

84. Sonenberg N, Hinnebusch AG. Regulation of translation initiation in eukaryotes: mechanisms and biological targets. Cell. 2009; 136:731-745.

85. Spilka R, Ernst C, Mehta AK, Haybaeck J. Eukaryotic translation initiation factors in cancer development and progression. Cancer Lett. 2013; 340:9-21.

86. Hinnebusch AG. eIF3: a versatile scaffold for translation initiation complexes. Trends Biochem Sci. 2006; 31:553-562.

87. Jackson RJ, Hellen CU, Pestova TV. The mechanism of eukaryotic translation initiation and principles of its regulation. Nat Rev Mol Cell Biol. 2010; 11:113-127.

88. Hershey JW. The role of eIF3 and its individual subunits in cancer. Biochim Biophys Acta. 2015; 1849:792-800.

89. Gao Y, Teng J, Hong Y, Qu F, Ren J, Li L, Pan X, Chen L, Yin $\mathrm{L}, \mathrm{Xu} \mathrm{D}$, Cui $\mathrm{X}$. The oncogenic role of EIF3D is associated with increased cell cycle progression and motility in prostate cancer. Med Oncol. 2015; 32:518.

90. Lin Z, Xiong L, Lin Q. Knockdown of eIF3d inhibits cell proliferation through $\mathrm{G} 2 / \mathrm{M}$ phase arrest in non-small cell lung cancer. Med Oncol. 2015; 32:183. 
91. Yu X, Zheng B, Chai R. Lentivirus-mediated knockdown of eukaryotic translation initiation factor 3 subunit D inhibits proliferation of HCT116 colon cancer cells. Biosci Rep. 2014; 34:e00161.

92. Fan Y, Guo Y. Knockdown of eIF3D inhibits breast cancer cell proliferation and invasion through suppressing the Wnt/ beta-catenin signaling pathway. Int J Clin Exp Pathol. 2015; 8:10420-10427.

93. Pan XW, Chen L, Hong Y, Xu DF, Liu X, Li L, Huang Y, Cui LM, Gan SS, Yang QW, Huang H, Qu FJ, Ye JQ, et al. EIF3D silencing suppresses renal cell carcinoma tumorigenesis via inducing $\mathrm{G} 2 / \mathrm{M}$ arrest through downregulation of Cyclin B1/CDK1 signaling. Int J Oncol. 2016.

94. Li H, Zhou F, Wang H, Lin D, Chen G, Zuo X, Sun L, Zhang X, Yang S. Knockdown of EIF3D suppresses proliferation of human melanoma cells through $\mathrm{G} 2 / \mathrm{M}$ phase arrest. Biotechnol Appl Biochem. 2015; 62:615-620.

95. Ren M, Zhou C, Liang H, Wang X, Xu L. RNAi-Mediated Silencing of EIF3D Alleviates Proliferation and Migration of Glioma U251 and U87MG Cells. Chem Biol Drug Des. 2015; 86:715-722.

96. Spilka R, Ernst C, Bergler H, Rainer J, Flechsig S, Vogetseder A, Lederer E, Benesch M, Brunner A, Geley S, Eger A, Bachmann F, Doppler W, et al. eIF3a is overexpressed in urinary bladder cancer and influences its phenotype independent of translation initiation. Cell Oncol (Dordr). 2014; 37:253-267.

97. Wang H, Ru Y, Sanchez-Carbayo M, Wang X, Kieft JS, Theodorescu D. Translation initiation factor eIF3b expression in human cancer and its role in tumor growth and lung colonization. Clin Cancer Res. 2013; 19:2850-2860.

98. Lee AS, Kranzusch PJ, Doudna JA, Cate JH. eIF3d is an mRNA cap-binding protein that is required for specialized translation initiation. Nature. 2016; 536:96-99.

99. Yamagata K, Sanders LK, Kaufmann WE, Yee W, Barnes CA, Nathans D, Worley PF. rheb, a growth factorand synaptic activity-regulated gene, encodes a novel Rasrelated protein. J Biol Chem. 1994; 269:16333-16339.

100. Inoki K, Li Y, Xu T, Guan KL. Rheb GTPase is a direct target of TSC2 GAP activity and regulates mTOR signaling. Genes Dev. 2003; 17:1829-1834.

101. Ilagan E, Manning BD. Emerging role of mTOR in the response to cancer therapeutics. Trends Cancer. 2016; 2:241-251.

102. Sobin L, Gospodarowicz K, Wittekind C. TNM Classification of Malignant Tumours, 7th Edition. UICC International Union Against Cancer. Wiley-Blackwell. 2009.

103. Sauter G, Algaba F, Amin M, Busch C, Cheville J, Gasser T. Noninvasive urothelial neoplasias: WHO classification of noninvasive papillary urothelial tumors. In: Eble N, Epstein J and Sesterhenn I, eds. World Health Organization classification of tumors Pathology and genetics of tumors of the urinary system and male genital organs. (Lyon: IARCC Press). 2004; 110.
104. Wisniewski JR, Zougman A, Nagaraj N, Mann M. Universal sample preparation method for proteome analysis. Nat Methods. 2009; 6:359-362.

105. Latosinska A, Vougas K, Makridakis M, Klein J, Mullen W, Abbas M, Stravodimos K, Katafigiotis I, Merseburger AS, Zoidakis J, Mischak H, Vlahou A, Jankowski V. Comparative Analysis of Label-Free and 8-Plex iTRAQ Approach for Quantitative Tissue Proteomic Analysis. PLoS One. 2015; 10: e0137048.

106. O`Donovan C, Martin MJ, Gattiker A, Gasteiger E, Bairoch A, Apweiler R. High-quality protein knowledge resource: SWISS-PROT and TrEMBL. Brief Bioinform. 2002; 3:275-284.

107. UniProt C. UniProt: a hub for protein information. Nucleic Acids Res. 2015; 43: D204-212.

108. Eng JK, McCormack AL, Yates JR. An approach to correlate tandem mass spectral data of peptides with amino acid sequences in a protein database. J Am Soc Mass Spectrom. 1994; 5:976-989.

109. Craig R, Beavis RC. TANDEM: matching proteins with tandem mass spectra. Bioinformatics. 2004; 20:1466-1467.

110. Deutsch EW, Mendoza L, Shteynberg D, Farrah T, Lam H, Tasman N, Sun Z, Nilsson E, Pratt B, Prazen B, Eng JK, Martin DB, Nesvizhskii AI, et al. A guided tour of the TransProteomic Pipeline. Proteomics. 2010; 10:1150-1159.

111. Keller A, Eng J, Zhang N, Li XJ, Aebersold R. A uniform proteomics MS/MS analysis platform utilizing open XML file formats. Mol Syst Biol. 2005; 1:2005-0017.

112. Wenger CD, Phanstiel DH, Lee MV, Bailey DJ, Coon JJ. COMPASS: a suite of pre- and post-search proteomics software tools for OMSSA. Proteomics. 2011; 11:1064-1074.

113. Keller A, Nesvizhskii AI, Kolker E, Aebersold R. Empirical statistical model to estimate the accuracy of peptide identifications made by MS/MS and database search. Anal Chem. 2002; 74:5383-5392.

114. Nesvizhskii AI, Keller A, Kolker E, Aebersold R. A statistical model for identifying proteins by tandem mass spectrometry. Anal Chem. 2003; 75:4646-4658.

115. Braisted JC, Kuntumalla S, Vogel C, Marcotte EM, Rodrigues AR, Wang R, Huang ST, Ferlanti ES, Saeed AI, Fleischmann RD, Peterson SN, Pieper R. The APEX Quantitative Proteomics Tool: generating protein quantitation estimates from LC-MS/MS proteomics results. BMC Bioinformatics. 2008; 9:529.

116. Franceschini A, Szklarczyk D, Frankild S, Kuhn M, Simonovic M, Roth A, Lin J, Minguez P, Bork P, von Mering C, Jensen LJ. STRING v9.1: protein-protein interaction networks, with increased coverage and integration. Nucleic Acids Res. 2013; 41:D808-815.

117. Makridakis M, Gagos S, Petrolekas A, Roubelakis MG, Bitsika V, Stravodimos K, Pavlakis K, Anagnou NP, Coleman J, Vlahou A. Chromosomal and proteome analysis of a new T24-based cell line model for aggressive bladder cancer. Proteomics. 2009; 9:287-298. 
118. Makridakis M, Roubelakis MG, Bitsika V, Dimuccio V, Samiotaki M, Kossida S, Panayotou G, Coleman J, Candiano G, Anagnou NP, Vlahou A. Analysis of secreted proteins for the study of bladder cancer cell aggressiveness. J Proteome Res. 2010; 9:3243-3259.

119. Frantzi M, Klimou Z, Makridakis M, Zoidakis J, Latosinska A, Borras DM, Janssen B, Giannopoulou I, Lygirou V, Lazaris AC, Anagnou NP, Mischak H, Roubelakis MG, et al. Silencing of Profilin-1 suppresses cell adhesion and tumor growth via predicted alterations in integrin and $\mathrm{Ca} 2+$ signaling in T24M-based bladder cancer models. Oncotarget. 2016;7:70750-70768. doi: 10.18632/ oncotarget. 12218.

120. Bitsika V, Roubelakis MG, Zagoura D, Trohatou O, Makridakis M, Pappa KI, Marini FC, Vlahou A, Anagnou NP. Human amniotic fluid-derived mesenchymal stem cells as therapeutic vehicles: a novel approach for the treatment of bladder cancer. Stem Cells Dev. 2012; 21:1097-1111.

121. Dull T, Zufferey R, Kelly M, Mandel RJ, Nguyen M, Trono D, Naldini L. A third-generation lentivirus vector with a conditional packaging system. J Virol. 1998; 72:8463-8471.

122. Roubelakis MG, Trohatou O, Roubelakis A, Mili E, Kalaitzopoulos I, Papazoglou G, Pappa KI, Anagnou NP. Platelet-rich plasma (PRP) promotes fetal mesenchymal stem/stromal cell migration and wound healing process. Stem Cell Rev. 2014; 10:417-428.

123. Huntley RP, Sawford T, Mutowo-Meullenet P, Shypitsyna A, Bonilla C, Martin MJ, O`Donovan C. The GOA database: gene Ontology annotation updates for 2015. Nucleic Acids Res. 2015; 43:D1057-1063. 